\title{
Experimental study of wave kinematics and wave load distribution on a vertical circular cylinder
}

\author{
Vested, Malene Hovgaard; Carstensen, Stefan; Christensen, Erik Damgaard
}

Published in:

Coastal Engineering

Link to article, DOI:

10.1016/j.coastaleng.2020.103660

Publication date:

2020

Document Version

Peer reviewed version

Link back to DTU Orbit

Citation (APA):

Vested, M. H., Carstensen, S., \& Christensen, E. D. (2020). Experimental study of wave kinematics and wave load distribution on a vertical circular cylinder. Coastal Engineering, 157.

https://doi.org/10.1016/j.coastaleng.2020.103660

\section{General rights}

Copyright and moral rights for the publications made accessible in the public portal are retained by the authors and/or other copyright owners and it is a condition of accessing publications that users recognise and abide by the legal requirements associated with these rights.

- Users may download and print one copy of any publication from the public portal for the purpose of private study or research.

- You may not further distribute the material or use it for any profit-making activity or commercial gain

- You may freely distribute the URL identifying the publication in the public portal

If you believe that this document breaches copyright please contact us providing details, and we will remove access to the work immediately and investigate your claim. 


\section{Journal Pre-proof}

Experimental study of wave kinematics and wave load distribution on a vertical circular cylinder

Malene Hovgaard Vested, Stefan Carstensen, Erik Damgaard Christensen

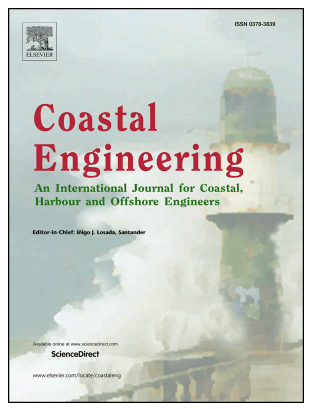

PII:

S0378-3839(19)30335-7

DOI:

https://doi.org/10.1016/j.coastaleng.2020.103660

Reference: CENG 103660

To appear in: Coastal Engineering

Received Date: 10 July 2019

Revised Date: 30 January 2020

Accepted Date: 2 February 2020

Please cite this article as: Vested, M.H., Carstensen, S., Christensen, E.D., Experimental study of wave kinematics and wave load distribution on a vertical circular cylinder, Coastal Engineering (2020), doi: https://doi.org/10.1016/j.coastaleng.2020.103660.

This is a PDF file of an article that has undergone enhancements after acceptance, such as the addition of a cover page and metadata, and formatting for readability, but it is not yet the definitive version of record. This version will undergo additional copyediting, typesetting and review before it is published in its final form, but we are providing this version to give early visibility of the article. Please note that, during the production process, errors may be discovered which could affect the content, and all legal disclaimers that apply to the journal pertain.

(C) 2020 Published by Elsevier B.V. 


\section{Credit Author Statement}

Malene Hovgaard Vested:

Conceptualization, Methodology, Investigation, Visualization, Writing- Original draft preparation

\section{Stefan Carstensen:}

Supervision, Methodology, Writing - Review \& Editing

\section{Erik Damgaard Christensen:}

Conceptualization, Supervision, Methodology, Validation, Writing- Reviewing and Editing, Project administration 
1 Experimental Study of Wave Kinematics and Wave Load Distribu-

2 tion on a Vertical Circular Cylinder

3

4 5

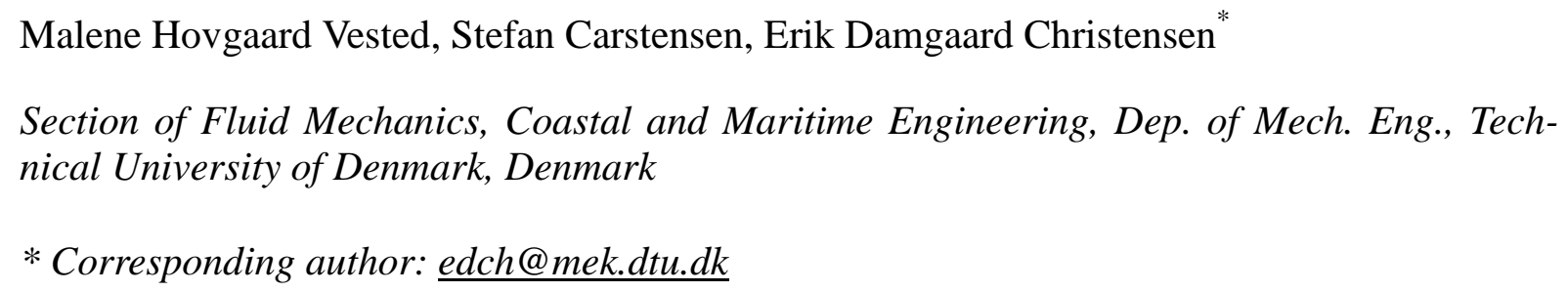

Keywords: Distributed Wave loads; Wave kinematics; Force harmonics; Force coefficients under waves

\section{ABSTRACT}

In this paper, we present measurements of force distribution on a vertical, circular cylinder exposed to shoaling regular waves. The cylinder was divided into four individual sections on which the wave loads were measured. Furthermore, we measured the wave kinematics with Particle Image Velocimetry (PIV) and with Laser Doppler Velocimetry (LDV) in a few reference cases. The force distribution was measured for twenty regular wave conditions and in all the cases the maximum force did not occur simultaneously on the individual sections of the cylinder. A decomposition of the total force in force harmonics showed the same tendencies for the total force as presented in literature. A decomposition of the force on individual cylindrical sections showed that the section at the surface had a significantly higher second force harmonic compared to the sections closer to the bed. Furthermore, we studied the local force coefficients on the individual sections on the cylinder. The inertia coefficient exhibited the same trend for all the individual sections. Estimated force coefficients from measured wave kinematics corresponded well with force coefficients in the literature. 
The development of the coastal and offshore areas are expected to be intensified, where the last couple of decades offshore wind development will be supplemented by a more general implementation of marine infrastructure in the near future. With a growing demand for offshore wind energy, wind turbines are now planned and installed at greater water depths. This means that the wind turbine foundations are subject to more harsh wave environments. Consequently, the wave loads on the wind turbine foundation play a larger role than previously.

(Sawaragi and Nochino, 1984) measured the impact forces from nearly breaking waves on a vertical cylinder. Regular waves shoaled on a laboratory slope of $1 / 15$ and 1/30 and forces were measured locally at five load cells along the length of the cylinder. They concluded that the maximum force happened roughly simultaneously on the measurement points on the cylinder. Similarly, (Tanimoto et al., 1986) measured the wave loads on a vertical cylinder from irregular waves shoaling on a slope of $1 / 30$. The wave loads were measured locally on the cylinder by strain gauges pasted on individual sections both above and below still water level. More recently, (Manjula et al., 2013) measured the vertical distribution of pressure on a vertical cylinder exposed to phase-focused breaking waves on a flat bed.

The pressure under undisturbed waves was measured by (Arntsen, 1998) at a location close to the bed. (Arntsen, 1998) noted that the pressure variation at the bottom is close to linear, and becomes more sinusoidal, even when the surface elevation is non-linear. Similarly, time series reported in (Sawaragi and Nochino, 1984), (Tanimoto et al., 1986) and (Manjula et al., 2013), showed the same trend.

Studies of the force distribution on a vertical cylinder from non-breaking waves are rare. (Kyte and Tørum, 1996) measured the local force above the still water level in a set-up similar to that of (Tanimoto et al., 1986). (Wienke and Oumeraci, 2005) studied the breaking wave impact on vertical and inclined circular cylinders. Pressure transducers measured the pressure around the cylinder. The results were used to derive a force model for the impact force with focus on plunging breaking waves. (Stansberg et al., 2012) measured the pressure impact from a breaking wave on a square section around a column. The measured pressure from the slamming event was accompanied by measurements of wave kinematics by PIV. 
62

Another study by (Roos et al., 2010) investigated wave forces on a vertical, circular cylinder by placing force sensors vertically along the top part of the cylinder. They emphasized the importance of wave steepness, but also concluded that the largest loads are often not caused by the tallest or steepest waves. They do not present the measured force distribution, which however may be derived from their experimental data.

For slender structures a Morison force model is often used to estimate the wave forces. Following Morison's equation, the wave load is computed as the sum of drag and inertia forces. The drag and inertia coefficients are established from experimental results. Many laboratory studies have been successful in determining the force coefficients including (Sarpkaya, 1976a) (Sarpkaya, 1976b) and (Justesen, 1989). In order to establish force coefficients, both force and the kinematics must be available. The force coefficients can be established from measured forces and kinematics in several ways. One method is the mean-least-square technique that seeks to minimize the difference between the measured forces and forces predicted through Morison's equation, as was described in (Sarpkaya, 1976a) and (Sarpkaya, 1976b). These classical experiments were conducted in oscillating tunnels with no free surface, rather than in wave flumes. Therefore, the determined force coefficients does not include the effect of orbital motion nor the effect of a free surface.

Studies in wave flumes have been performed by (Chakrabarti, 1980) and (Bearman et al., 1985), who measured the wave loads on a vertical cylinder. In another study by (Mackwood et al., 1997) the wave loads on a large scale cylinder was investigated. (Chakrabarti, 1980) measured the wave forces on a vertical cylinder in a wave flume and determined the force coefficients. The force coefficients compared well to the ones reported by (Sarpkaya, 1976a), even though the study by (Sarpkaya, 1976a) was plane oscillatory. For small KC numbers of $\mathrm{KC}<15$, however, the inertia coefficient $\mathrm{C}_{\mathrm{M}}$ was larger than in the plane oscillatory case.

In the case of shoaling waves, it has been demonstrated that Morison's equation combined with linear theory generally predicts maximum forces well for nonbreaking events, if the wave steepness is mild. For breaking and post-breaking waves, however, Morison's equation based on linear theory as well as stream function theory tend to underestimate the total forces. This has been shown in several studies, including (Kriebel, 1998), (Luck and Benoit, 2004) and (Stansby et al., 2013). For bottom-mounted circular cylinders the use of the Morison 
equation has often been used, as well as suggestions for new models have been presented in for instance (Aristodemo et al., 2011). Here the forces were obtained with a battery of pressure sensors located around the external contour of a circular cylinder. The use of VOF (volume of Fluid )- based methods has also been uses extensively to assess wave forces and wave run-up such as (Christensen and Hansen, 2005), (Christensen et al., 2005), (Alfonsi et al., 2013), and (Tomaselli and Christensen, 2017)

Higher force harmonics were studied based on a very large data set in (Kristiansen and Faltinsen, 2017) and comparisons were made to the FNV theory presented in (Faltinsen et al., 1995). Their study was carried out over plane bed and therefore the ratio of wave height over water depth should be smaller than 0.55 according to (Nelson, 1994). As not all test cases fulfilled this criteria breaking took place and had some influence on the force harmonics at high wave steepness. The FNV theory calculates the forces based on a theory for the wave kinematics. A direct method of evaluating the integrals together with the Stokes fifth-order wave theory gave a better agreement with the measurements compared to a purely third order methodology. This indicates that accurate wave kinematics and its treatment is important for the accuracy of the wave force predictions.

In experiments, laser and optical technologies as Laser Doppler Velocimetry (LDV) (earlier often called LDA) and Particle Image Velocimetry (PIV) have been used to measure velocity fields under waves. Among the first studies of wave velocities measured with PIV are (Greated et al., 1992), (Perlin et al., 1996), (Chang and Liu, 1998), (Chang and Liu, 1999) and (Emarat et al., 2000), followed by (Grue et al., 2003), (Kimmoun et al., 2004), and more recently by (Belden and Techet, 2011), (Emarat et al., 2012), (André and Bardet, 2014) among others.

An early example of accelerations measured by use of PIV is given by (Jakobsen et al., 1997), who studied standing waves in a tank. The method involved a set of four cameras, since the sample rate of a single camera was not adequate for obtaining accelerations. In a similar study by (Jensen et al., 2001), a two-camera PIV setup was used to measure local accelerations under regular, deep-water waves with velocities sampled at both cameras. The time increment between the sampled velocities was $0.06 \mathrm{~s}$ and (Jensen et al., 2001) found that the standard deviation on the accelerations was $2 \%$ in the best case. (Jensen and Pedersen, 2004) describe 
the optimization of measuring accelerations by use of PIV. In recent years, the development in laser- and optical techniques have pushed the limits of the sample rate available to PIV techniques. Our experimental set-up thus provides for a PIV sample rate of close to $100 \mathrm{~Hz}$, which we found adequate for assessment of accelerations. To this end, this study presents both measurements of wave loads and of wave kinematics, which allow force coefficients to be established.

Because of the requirement of high sample rates, most studies of wave accelerations have employed LDV. These include a study of deep water waves by (Easson and Greated, 1985), a study of breaking waves on various slopes by (Griffiths et al., 1992) and a study of phasefocused waves by (Kim et al., 1992). In Morison's equation, the inertia term includes the material derivative, which is the sum of local acceleration and convective acceleration. The importance of the convective acceleration has been investigated in a number of studies. (Swan et al., 2002) investigated accelerations under steep waves by use of LDV. They found that the maximum value of inertia loading was primarily dependent on the local horizontal accelerations and that the convective acceleration was negligible. (Jensen et al., 2007) studied the vertical acceleration under steep irregular waves by use of PIV. They found that the convective acceleration was at the same order of magnitude as the local acceleration and therefore could not be neglected.

In this study, we investigated the vertical distribution of wave loads on a vertical, circular cylinder for twenty regular wave conditions. Further, the force coefficients for local sections on a vertical, circular cylinder were derived from local measurements of wave loads and wave kinematics. The wave kinematics were measured by use of Particle Image Velocimetry, PIV. (Vested et al., 2018a) suggested a methodology for the local force measurement that was used in our study too. The novelty of this work is two-fold: (i) We investigated the force distribution on a vertical, cylinder by measuring loads on individual sections through load cells (ii) We established force harmonics and force coefficients for individual sections based on measured loads and wave kinematics.

158 This paper is structured as follows. First, we present the methodology for the measurement of 159 local wave loads on the cylinder as well as the PIV technique used to measure wave kinemat160 ics in section 2. Section 3 shows examples of the measured wave kinematics and comparisons 
161 between LDV and PIV methodologies. The wave loads and its distribution over the water

162

163

164

165

166

167

168

169

170

171

172

173

174

175

176

177

178

179

180

181

182

183

184

185

186

187 188

189

190

column is studied in section 4. The measured forces and kinematics are exploited to determine local force coefficients for the individual sections on the cylinder in section 5. Finally, conclusions are drawn in section 6.

\section{Methodology for measuring wave loads and wave kinematics}

\subsection{Experimental setup}

A series of wave experiments were conducted in a wave-current flume at the Hydraulic Laboratory of the Technical University of Denmark. The flume had a length of $28.0 \mathrm{~m}$, width of $0.60 \mathrm{~m}$ - and a depth of $0.80 \mathrm{~m}$. Waves were generated by a piston-type wave paddle and the water depth at the wave paddle was $h_{A}=0.515 \mathrm{~m}$. In order to investigate steep and breaking waves, an inclined, smooth seabed of slope 1/25 was installed in the wave flume. A vertical, circular cylinder was located on the sloping bed $19.8 \mathrm{~m}$ from the wave paddle. The still water depth at the cylinder was $h_{C}=0.205 \mathrm{~m}$. During the measurements of wave kinematics, the cylinder was removed and the undisturbed wave was studied. Fig. 1 shows the experimental setup for the measurements of wave loads, Fig. 1a, and of wave kinematics, Fig. 1 b.

The surface elevation was measured relative to the MWL at six positions in the flume with resistance wave gauges. The wave gauges were built in-house and measured the surface elevation with an accuracy of $1 \mathrm{~mm}$. Four wave gauges were placed upstream of the cylinder at positions $-5 \mathrm{~m},-3.5 \mathrm{~m},-1.5 \mathrm{~m}$ and $-0.5 \mathrm{~m}$ relative to position $\mathrm{C}$ at the cylinder (or centre of PIV window), one wave gauge was positioned next to position $\mathrm{C}$ at and one wave gauge was positioned $0.5 \mathrm{~m}$ downstream of position C. All wave gauges were located at the centreline of the flume, except the one next to position $\mathrm{C}$, which was positioned with equal distance to the sidewall and the cylinder or PIV window.

a) 


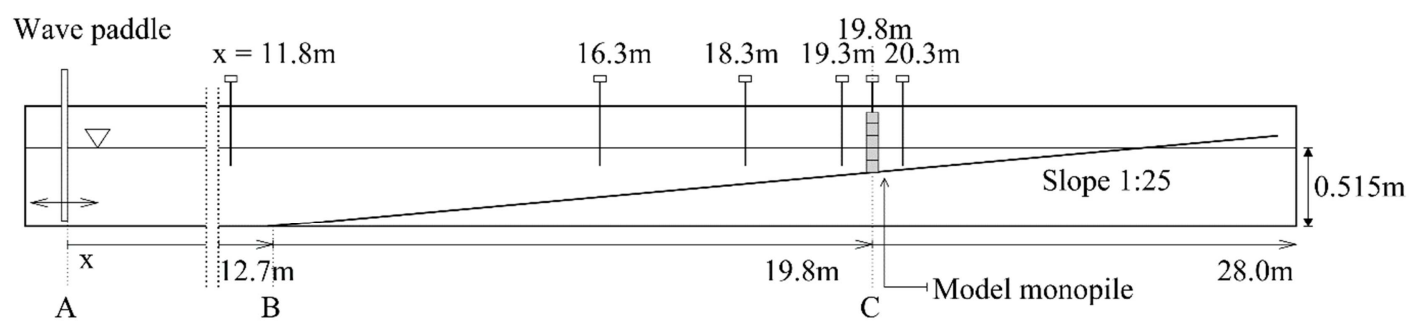

192 b)

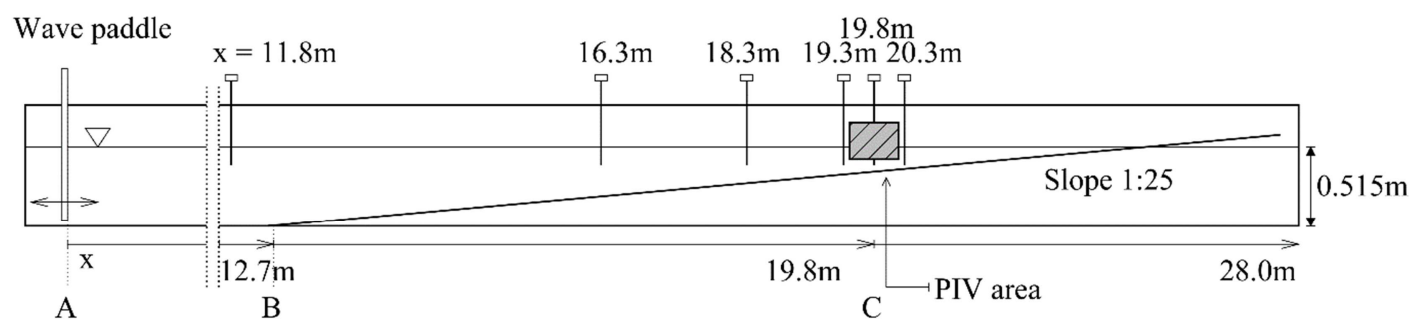

194 Fig. 1 Sketch of the wave flume. Waves were generated by a wave paddle to the left and waves travelled on flat bed for 12.7 m before shoaling along a 1/25-slope. Six wave gauges measured the surface elevation. (a) The vertical, circular cylinder positioned $19.8 \mathrm{~m}$ from the wave paddle at a water depth of $h_{C}=0.205 \mathrm{~m}$. (b) PIV window centred $19.8 \mathrm{~m}$ from the wave paddle.

The circular cylinder consisted of seven transparent cylindrical acrylic (PMMA)-tubes with an outer diameter of $80 \mathrm{~mm}$, a wall thickness of $5.6 \mathrm{~mm}$, and with a height of $80 \mathrm{~mm}$, as shown in the sketch in Fig. 2a. Each two sections connected by a load cell, and the top and bottom sections were fixed to a steel structure, which was clamped to the flume. Fig. $2 b$

204 shows a photograph of the cylinder mounted in the wave flume. In the sloping bed, a circular 205 hole allowed the cylinder to be fixed to a steel structure below the bed. In order for the cylin206 der to move free from the bed, the diameter of the hole was $2 \mathrm{~mm}$ larger than the diameter of 207 the pile, and furthermore, the bottom of the first section was raised $2.5 \mathrm{~mm}$ above the bed at 208 the centre line of the cylinder. We measured the natural frequency of the vertical cylinder 41 209 Hz with a hammer test. 


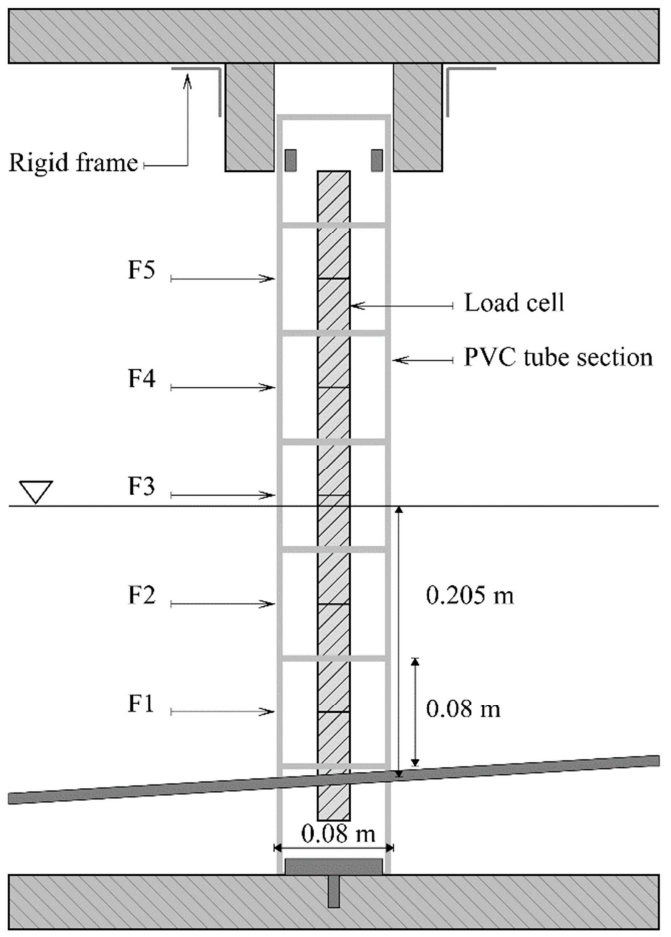

a)

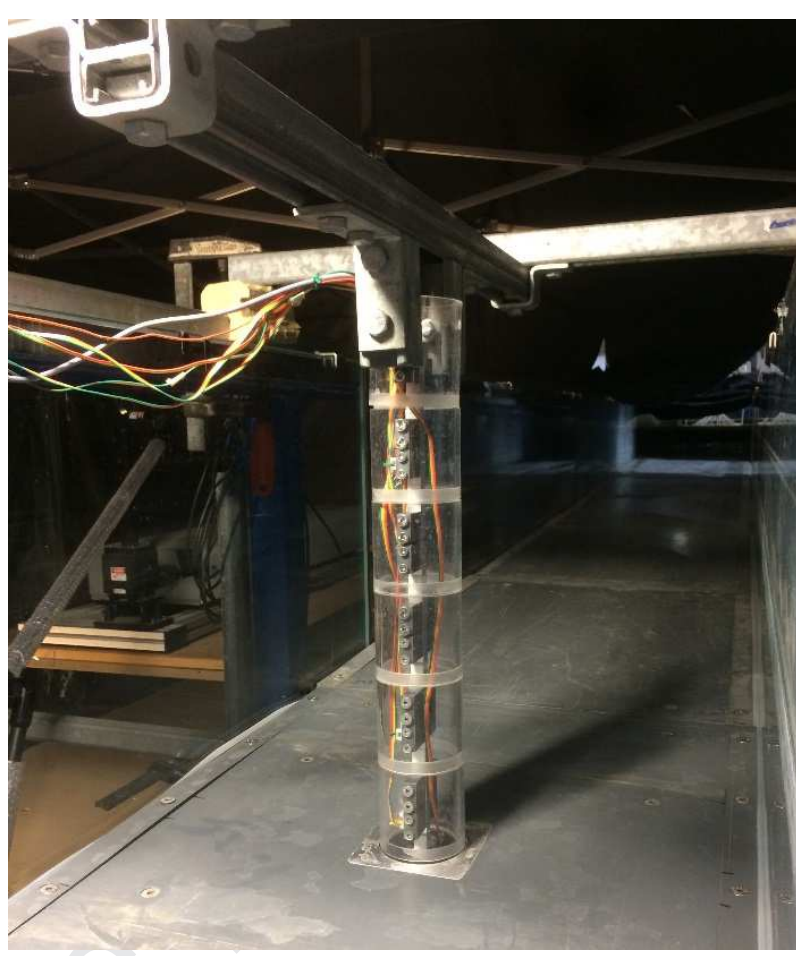

b)

213 Fig. 2 Sketch of the cylinder. a) Local forces F1 through F5 were measured on the cylindrical 214 sections connected by load cells. The section number 5 was above water in all wave condi215 tions and thus measurements on this section are omitted in the following. b) Photograph of 216 the vertical cylinder installed in the wave flume.

218 Surface elevations and force measurements were sampled at $1000 \mathrm{~Hz}$. Subsequently, the force 219 signal was filtered by applying a Hamming filter with a cut-off frequency of $10 \mathrm{~Hz}$, which 220 was well below the natural frequency and below the electric power grids mains frequency of $22150 \mathrm{~Hz}$. Each load cell measured the shear force between two cylindrical sections. The high 222 sampling rate collecting raw data at $1000 \mathrm{~Hz}$ might seem unnecessary, but does not cause any 223 problems to the acquisition systems and it was considered safe to be far from the filtering fre224 quency.

226 From the measured shear forces $V_{i}$, the local forces $F_{i}$ were obtained through the relation:

$$
F_{i}=V_{i}-V_{i+1}
$$


The set-up thus facilitated five force measurement points, which were denoted $F_{1}$ through $F_{5}$ in the following, counting from the bottom. The fifth section, however, remained above the surface elevation under the measured wave conditions and therefore the wave loads on this section are omitted in the following. The two lower sections, sections 1 and 2, were constantly submerged in all wave conditions, while sections 3 and 4 were submerged depending on the surface elevation $\eta(t)$. During the tests the surface elevation was relative to the MWL, as setup and set-down took place along the slope. The total force $F_{t o t}$ was found by the sum of the local forces:

$$
F_{\text {tot }}=\sum_{i=1}^{N} F_{i}
$$

237

$$
y_{i, p a}(t)=\frac{1}{2} L_{i}(t)+(i-1)\left(L S+\Delta z_{2}\right)+\Delta z_{1}-\left(h_{C}+M W L\right)
$$

From a static load test, we found that local forces were measured within $0.02 \mathrm{~N}$, which corresponds to less than $2 \%$ of the total wave load for the testes wave conditions.

For smaller waves, the three lower sections were affected by the waves, while for larger waves, the water surface extends to a higher elevation and four sections were affected by the wave forces. For the section exposed to the free surface the wetted length of the section $L_{i}(t)$ is described by:

$$
L_{i}(t)=h_{C}+M W L+\eta(t)-\Delta z_{1}-(i-1) \cdot\left(L S+\Delta z_{2}\right)
$$

where $i$ is the section number exposed to the free surface, $h_{C}$ is the still water depth, $\eta(t)$ is the surface elevation relative till MWL, $\Delta z_{1}$ is the gap between the bed and the cylinder and $L S$ is the length of each section and $\Delta z_{2}$ is the gap between each two sections. The mean water level, MWL was computed for the selected 40 waves. The points of attack of the local wave loads are assumed to be at the midpoint of the wetted lengths: 


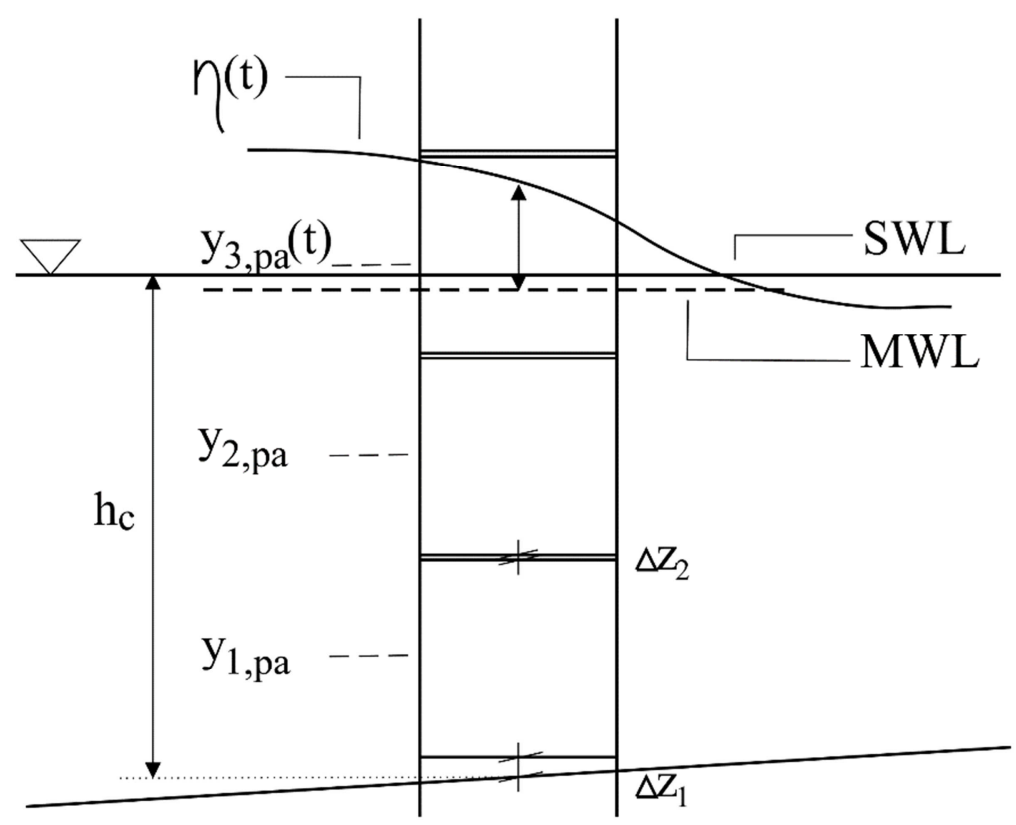

252 Fig. 3 Illustration of the postion of cylindrical sections relative to the SWL,MWL and surface 253 elevation $\eta(t)$.

\subsection{Wave conditions and experimental procedure}

256 Wave loads were measured, for the wave conditions listed in Tab. 1. The table additionally

257 lists experiments that were repeated in order to measure the undisturbed wave kinematics. The 258 sloping bed allowed to generate steep non-breaking waves at the cylinder. Effect of breaking 259 waves was not the focus of the study, but we still targeted also steep waves to assess the effect 260 of non-linear waves. In a couple of the cases, case 11 and 12, the waves had a tendency to 261 break after but close to the circular cylinder.

263 Dimension analyses indicated that the force could be written as function of 6 parameters:

$$
\frac{F}{\rho g D^{3}}=f\left(K C, \frac{D}{L}, k h, R e, \alpha\right)
$$

264 where $K C$ is the Keulegan-Carpenter number found as $K C=\frac{\pi H}{D} \operatorname{coth}(k h)$ from first order 265 stokes theory at the mean water level. $\frac{D}{L}$ is the ratio between the diameter and the wave length 266 that is important for diffraction effects. $k h$ represents the ratio of depth over wave length,

267 where $k=\frac{2 \pi}{L}$. This parameter is connected to a dimensionless angular frequency $\frac{\omega^{2} h}{g}$ through 
268

269

270

271

272

273

274

275

276

277

278

279

the dispersion relation. $R e$ is the Reynolds number, $\alpha$ the slope of the bed. The range of $D /$ $L$ was in all the proposed cases small indicating that diffraction effects would be small.

Another parameter that has been recognized as important for circular-cylinder flow is the viscous frequency parameter $\beta$, (Sarpkaya, 1976c). The viscous parameter is the ratio of the Reynolds number to the Keulegan-Carpenter number, $\beta=R e / K C$. In (Bearman et al., 1986) the effect was studied for oscillatory flows at low KC-number. Reynolds number effects were disregarded as the data was assumed to be too scarce and variation of the slope was not studied in detail so the relationship was reformulated as follows:

$$
\frac{F}{\rho g D^{3}}=f(K C, k D, k h)
$$

$K C$ is as outlined above also a measure of the ratio of wave height over diameter. In deep water the $K C$ at the MWL reduces to $K C=\frac{\pi H}{D}$ as $\operatorname{coth}(\mathrm{kh}) \rightarrow 1$ for $h \rightarrow \infty . D / L$ was reformulated to $k D$. Another parameter that could be important is the Ursell parameter, but it will depend on other already defined dimensionless variables:

$$
U r=\frac{H L^{2}}{h^{3}}
$$

In some cases it was found convenient to present the force as $\frac{F}{\rho g H D^{2}}$ instead of $\frac{F}{\rho g D^{3}}$ where the wave height has been used as well as the diameter.

In the above analyses the $\mathrm{KC}$ number was found from first order stokes wave theory. Using the maximum velocity and the full wave period has also been used. For instance, (Kristiansen and Faltinsen, 2017) also presented KC numbers based on the maximum and minimum velocities from third and fifth order stokes theory, $K C_{3}^{+}, K C_{3}^{-}, K C_{5}^{+}, K C_{5}^{-}$, respectively. They did not use the $\mathrm{KC}$-number in the later analyses, and therefore it was mainly indicative for the parameter space that was studied. In our study we made an attempt to derive force coefficients for different $\mathrm{KC}$-numbers based on both measured and calculated wave kinematics.

In the following we discuss two different expressions of the KC-number that could be used in the analyses: 


$$
\begin{gathered}
K C=\frac{U_{m} T}{D} \\
K C_{a}=\frac{2 \pi a}{D}
\end{gathered}
$$

294 where $U_{m}$ is the maximum velocity, $T$ the wave period (or oscillation period), $D$ the diameter 295 of the circular cylinder, and a the amplitude of the particle motion. The eqs. (2.8) is the defi296 nition of the KC number while eqs. (2.9) a rearrangement based on sinusoidal motion.

297 The KC number is typically defined from the maximum velocity in a sinusoidal oscillation, as 298 shown in eqs. (2.8). In an oscillation that is not sinusoidal, this definition might not be the best choice. A non-linear wave crest is shorter than the wave trough. This leads to higher velocities under the wave crest for a shorter period, and smaller velocities under the wave trough for a longer period than half the wave period. Just using the maximum non-linear velocity would increase the $\mathrm{KC}$ number compared to the maximum velocity from first order stokes theory. Eqs. ( 2.9) finds the KC-number from the amplitude of the particle motion. First order stokes theory results in the same $\mathrm{KC}$ for the two formulation. This is not the case for nonsinusoidal motion and therefore not the case under non-linear waves. The effect of the oscillating motion has often been related to the development of vortices and vortex shedding on the lee side of the circular cylinder. The vortex development is related to the length of the particle track. For instance, separation start to occur for $K C \sim 6-7$, (Williamson, 1985), which corresponds to $a / D \sim 1$.

In Fig. 4, left panel, the KC-number was found from maximum and minimum velocities at the surface estimated with stream function theory, (Rienecker and Fenton, 1981). It was compared to first order stokes theory and the average of the $K C_{S F, \max }$ and $K C_{S F, \min }, K C_{S F, \text { ave }}$. As expected, the KC-number from stream function theory for maximum velocity increased more than the first order theory, and using the minimum velocity gave a smaller increase. The average of the two estimates from stream function theory increased slightly more with $H / L$, than the first order theory. On the right panel we estimated the KC-number through an integration of the horizontal particle track. If the integration followed the particle, we find $K C_{a, t o t}$ and if the integration only uses the local horizontal velocity at the centre-line, we find $K C_{a, l o c}$. Following the particle resulted in larger $\mathrm{KC}$ compared to first order theory as the velocity follows the wave and therefore the velocity tends to be positive for a large time. Integration of the local velocity gave a smaller KC than found from first order theory. As it could be argued as 
an approximation it is a combination of the two that actual forms the vortex on the lee side of the structure, the average of the two, $K C_{a, a v e}$, is also shown. This gave a slightly higher $\mathrm{KC}$ than first order wave theory. We saw that just using the maximum velocity and the full wave period gave a $\mathrm{KC}$ that could be twice the $\mathrm{KC}$ found from first order theory. Average values from both approaches gave a $\mathrm{KC}$ that was close to first order $\mathrm{KC}$.
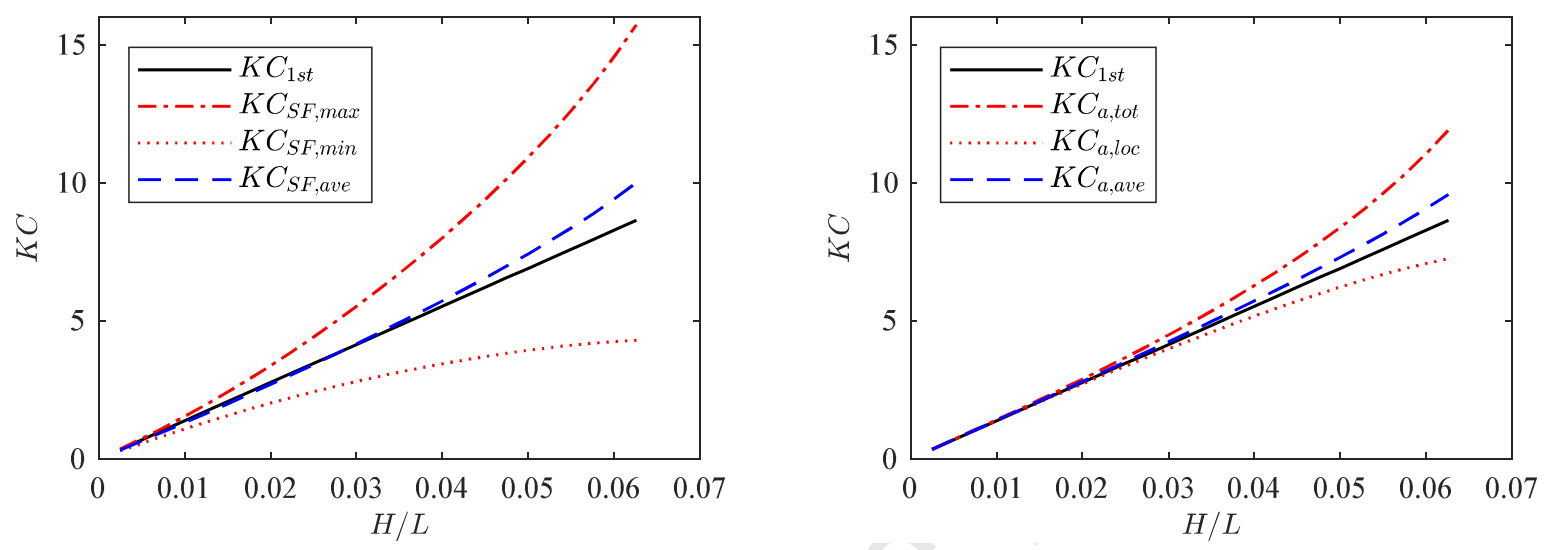

Fig. 4 Estimation of KC as function of the wave steepness H/L. Left panel: KC number found from first order stokes theory and maximum and minimum velocities at the surface from stream function theory. Right panel: KC number based on horizontal particle path. $k h=0.65$, $h / D=2.56$.
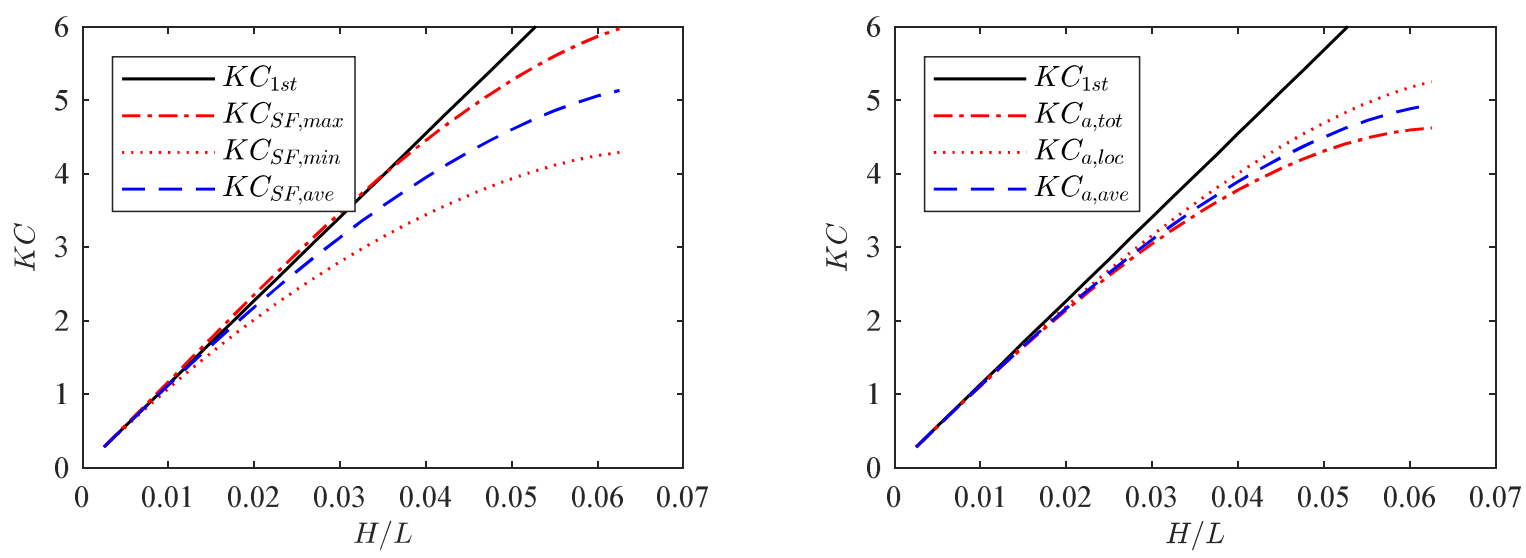

333 Fig. 5 Estimation of KC as function of the wave steepness $H / L$ at the sea bed. Left panel: KC

334 number found from first order stokes theory and maximum and minimum velocities at the 335 surface from stream function theory. Right panel: KC number based on horizontal particle 336 path. $k h=0.65, h / D=2.56$. 
Fig. 5 shows a similar analyses for $\mathrm{KC}$ at the sea bed. Here first order theory gave higher $\mathrm{KC}$ numbers compared to stream function theory. First order wave components give larger contribution to the velocity at the bed, and when the wave is expected to respresented by only

340 the first component the velocities will consequently be larger at the sea bed.

342 Based on these analyses we found that the KC-numbers based on first order theory gave a

343 better or at least as good representation of the processes as KC-numbers based on accurate 344 non-linear theory. Therefore the $\mathrm{KC}$ number will be related to the first order theory at the 345 specific location in the water coloumn.

Tab. 1 Regular wave conditions for the measurement of local wave loads on a vertical, circu-

348 lar cylinder. The waves were shoaling along a 1/25-sloping bed and the water depth at the

349 cylinder location was $0.205 \mathrm{~m}$. Selected wave conditions, marked by $X$, were repeated and the 350 undisturbed wave kinematics was measured by use of PIV.

\begin{tabular}{llllllllrrrr}
\hline Case & $\begin{array}{l}\mathrm{T} \\
{[\mathrm{s}]}\end{array}$ & $\begin{array}{l}\mathrm{H} \\
{[\mathrm{m}]}\end{array}$ & $\begin{array}{l}\omega^{2} h \\
/ g\end{array}$ & $\begin{array}{l}\mathrm{H} / \mathrm{h} \\
{[-]}\end{array}$ & $\begin{array}{c}k h \\
{[-]}\end{array}$ & $\begin{array}{l}k D \\
{[-]}\end{array}$ & $\begin{array}{c}\mathrm{H} / \mathrm{L} \\
{[-]}\end{array}$ & $\begin{array}{r}\mathrm{KC} \\
{[-]}\end{array}$ & $\begin{array}{r}\mathrm{Ur} \\
{[-]}\end{array}$ & $\begin{array}{l}\mathrm{Re} \\
{[-]}\end{array}$ & $\mathrm{PIV}$ \\
\hline 1 & 1 & 0.033 & 0.82 & 0.16 & 1.05 & 0.41 & 0.027 & 1.7 & 5.9 & 11,000 & $\mathrm{X}$ \\
2 & 1 & 0.068 & 0.82 & 0.33 & 1.05 & 0.41 & 0.056 & 3.4 & 11.6 & 21,000 & \\
3 & 1 & 0.086 & 0.82 & 0.42 & 1.05 & 0.41 & 0.070 & 4.3 & 14.7 & 27,000 & \\
4 & 1 & 0.100 & 0.82 & 0.49 & 1.05 & 0.41 & 0.082 & 5.0 & 17 & 34,000 & $\mathrm{X}$ \\
5 & 1.2 & 0.039 & 0.57 & 0.19 & 0.84 & 0.33 & 0.025 & 2.2 & 10.7 & 11,000 & $\mathrm{X}$ \\
6 & 1.2 & 0.074 & 0.57 & 0.36 & 0.84 & 0.33 & 0.048 & 4.2 & 20.6 & 22,000 & \\
7 & 1.2 & 0.102 & 0.57 & 0.50 & 0.84 & 0.33 & 0.066 & 5.9 & 27.4 & 30,000 & $\mathrm{X}$ \\
8 & 1.2 & 0.119 & 0.57 & 0.58 & 0.84 & 0.33 & 0.077 & 6.8 & 32.7 & 38,000 & \\
9 & 1.5 & 0.038 & 0.37 & 0.19 & 0.65 & 0.25 & 0.019 & 2.6 & 17.6 & 13,000 & $\mathrm{X}$ \\
10 & 1.5 & 0.062 & 0.37 & 0.30 & 0.65 & 0.25 & 0.031 & 4.3 & 29.1 & 20,000 & \\
11 & 1.5 & 0.104 & 0.37 & 0.51 & 0.65 & 0.25 & 0.052 & 7.2 & 48.5 & 34,000 & \\
12 & 1.5 & 0.170 & 0.37 & 0.83 & 0.65 & 0.25 & 0.085 & 11.7 & 76.3 & 55,000 & \\
13 & 2 & 0.035 & 0.21 & 0.17 & 0.47 & 0.18 & 0.013 & 3.1 & 29.6 & 10,000 & \\
14 & 2 & 0.046 & 0.21 & 0.22 & 0.47 & 0.18 & 0.017 & 4.1 & 40 & 14,000 & \\
15 & 2 & 0.083 & 0.21 & 0.41 & 0.47 & 0.18 & 0.030 & 7.4 & 73 & 27,000 & \\
16 & 2 & 0.115 & 0.21 & 0.56 & 0.47 & 0.18 & 0.042 & 10.3 & 99.1 & 32,000 & \\
17 & 2.5 & 0.029 & 0.13 & 0.14 & 0.37 & 0.14 & 0.008 & 3.2 & 40.4 & 9,000 & \\
18 & 2.5 & 0.057 & 0.13 & 0.28 & 0.37 & 0.14 & 0.016 & 6.3 & 79.5 & 19,000 & \\
19 & 2.5 & 0.104 & 0.13 & 0.51 & 0.37 & 0.14 & 0.030 & 11.5 & 143.6 & 15,000 & \\
20 & 2.5 & 0.152 & 0.13 & 0.74 & 0.37 & 0.14 & 0.044 & 16.8 & 213.3 & 17,000 & \\
\hline
\end{tabular}

352 The experimental procedure included three steps. Firstly, regular waves were generated for a 353 minimum of 20 minutes, following the procedure of (Ting and Kirby, 1994), after which the 
wave conditions in the flume were considered as steady state. Secondly, the measurement of wave loads had a duration of 5 minutes. Thirdly, after the wave paddle stopped, a stabilization phase of 20 minutes allowed for the water surface to come to rest before the next experiment was conducted. During all three steps, the surface elevation and the loads on the cylinder were measured. The wave gauges were calibrated before and after the experiment, such that any changes in calibration constants were discovered. Due to the wave breaking on the slope the use of wave absorption at the wave maker was not found necessary.
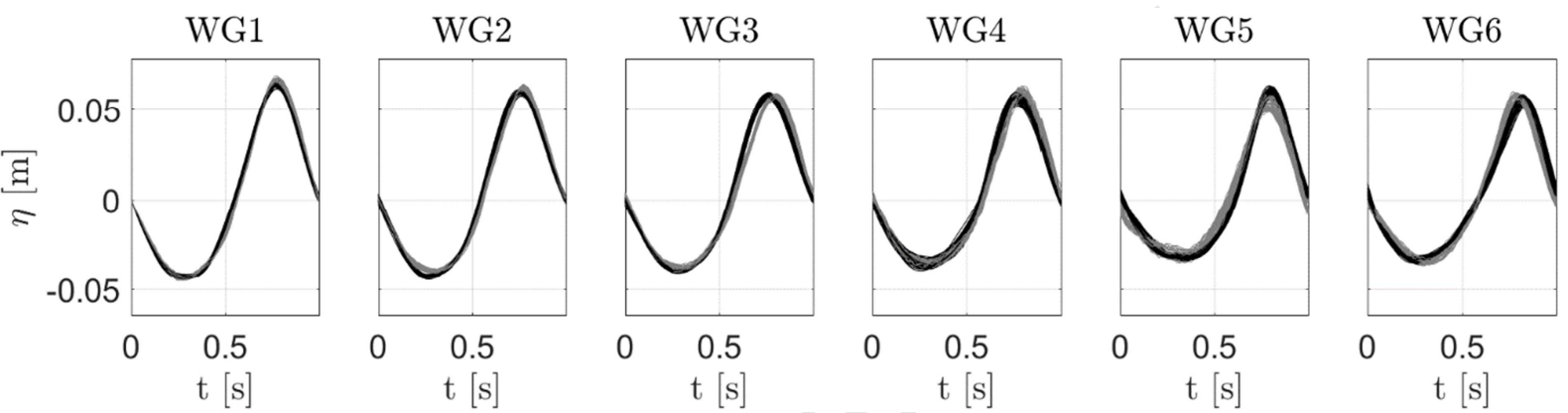

363

Fig. 6 Shoaling of undisturbed wave, wave period $T=1.0$ s, wave height $H=0.10 \mathrm{~m}$ (test 4).

Black line and grey line represent two runs with the same input parameters at the wave paddle. The difference in wave height before the slope at WG1 is $1 \%$, while at the PIV measurement section at WG5, the difference in wave height is $5 \%$

367 For the data analysis, 40 consecutive waves were analysed. 40 consecutive waves provided stable standard deviation of the wave height of consecutive waves. As we could not measure wave forces and undisturbed wave kinematics at the same time we had to assume that it was possible to repeat the same conditions. The assumption of repeatability of the wave paddle, and therefore the wave conditions, was tested by comparison of two runs with the same signal given to the wave paddle. Fig. 6 shows the surface elevation for two runs with same input parameters to the wave paddle without the cylinder installed on the slope. Note the steepening of the wave due to the shoaling on the slope. The overlap between the surface elevations indicated a high repeatability of the wave conditions. The wave gauge just before the slope at $\mathrm{x}=$ $11.8 \mathrm{~m}, \mathrm{WG} 1$, shows a difference in wave height at around $1 \%$ between the two runs. As the waves propagated up the slope, the difference between the two runs increased such that at WG5, the difference in wave height between the two runs was around $5 \%$. The reason for the increased difference could be due to increased turbulence levels during shoaling or/and due to 
380

381

382

383

384

385

386

387

388

389

390

391

392

393

394

395

396

397

398

399

400

401

402

403

404

405

minor reflections from the slope. The reflections might be affected by the turbulence that induces variations.

Fig. 7 compares two runs for which the one is with the cylinder installed and the other without the cylinder. A larger difference between the two runs was now observed, especially at wave gauges WG3, WG4 and WG5, which were located in the immediate neighbourhood of the cylinder. In particular, the trough was affected by the cylinder and a diffraction pattern formed. The difference between the two runs increased to around $10 \%$ at WG5. The figures Fig. 6 and Fig. 7 thus show that the difference between two runs with same input parameter to the wave paddle waves increased when the cylinder was included in one of the runs. This show that the difference was related to interaction between the waves and the cylinder and not caused by lack of repeatability by the wave paddle.
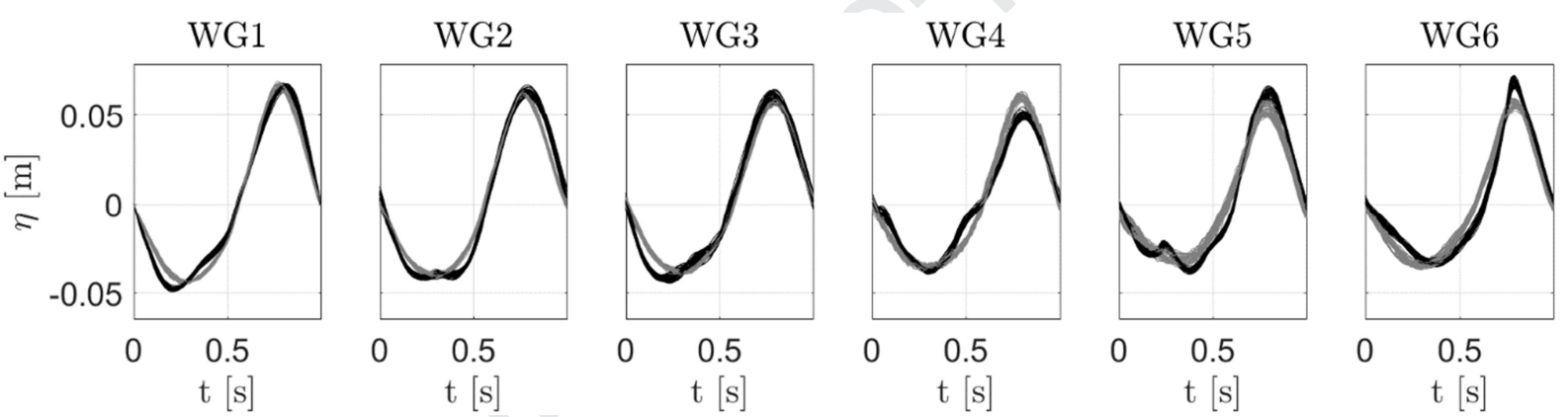

Fig. 7 Shoaling of wave with cylinder (black) and undisturbed shoaling wave (grey), wave period $T=1.0$ s, wave height $H=0.10 \mathrm{~m}$ (test 4). The difference in wave height before the slope at WG1 is 4\%, while at the PIV measurement section at WG5, the difference in wave height is $10 \%$.

\section{Wave kinematics}

Particle Image Velocimetry (PIV) was employed to measure wave kinematics for selected wave conditions, listed in Tab. 1. Fig. 8 shows a photograph of the setup and Fig. 9 shows a cross-sectional sketch of the flume and the PIV measurement setup. The Dantec Dynamics PIV measurement system consisted of a 4 Mpix camera and a dual-cavity Nd:YAG laser emitted green light of $532 \mathrm{~nm}$. The camera had a $50 \mathrm{~mm}$ lens and a pixel resolution of $2320 \times 1726$. The glass wall of the flume allowed for the camera to record the flow from outside the flume. The camera sampled double frame pictures at $96 \mathrm{~Hz}$ and with $5 \mathrm{~ms}$ between 
406 the two frames. A $45^{\circ}$ tilted mirror placed below the inclined bed established a vertical laser 407 sheet by reflection of the horizontal laser sheet. In the inclined bed, a glass window allowed 408 the laser sheet to illuminate the water in the measurement area. The thickness of the laser 409 sheet ranged from $2 \mathrm{~mm}$ to $2.8 \mathrm{~mm}$ in the measurement area. The water was seeded with sil410 ver-coated hollow glass spheres with a neutral buoyancy and a mean diameter of $10 \mu \mathrm{m}$. The 411 silver coating on the seeding particles ensured a high reflection. To capture the entire water 412 column, each experiment was conducted twice with two different window positions, labelled 413 window A and window B, as sketched in Fig. 9.

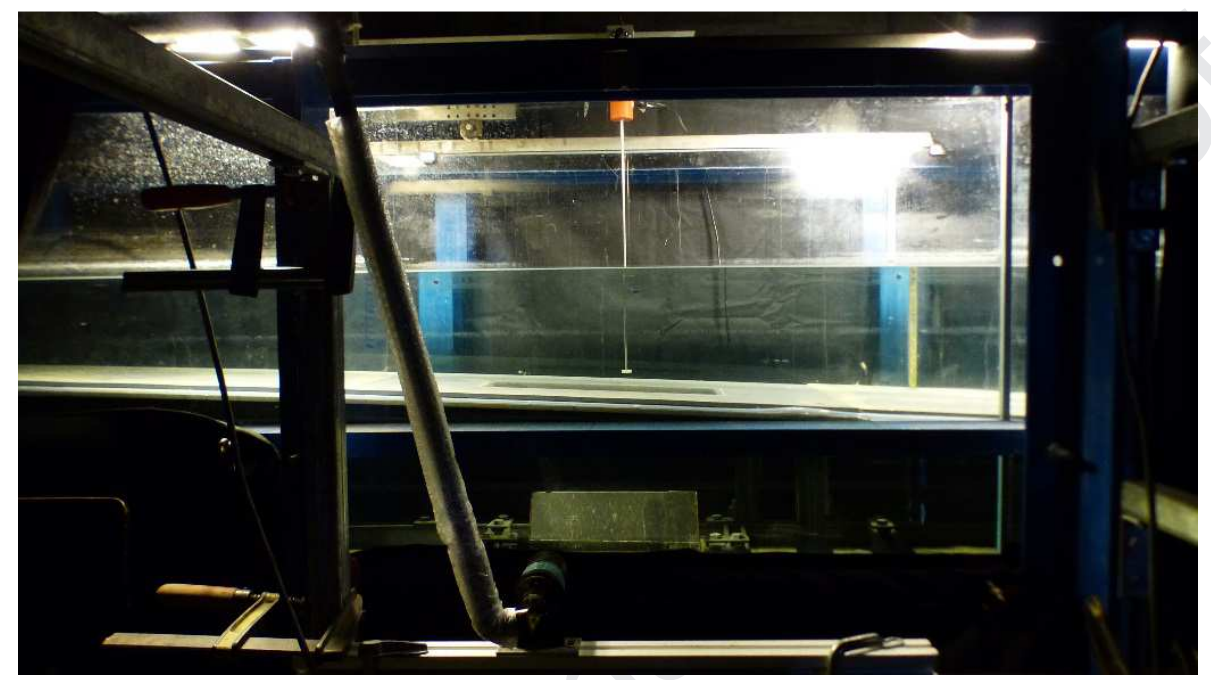

415 Fig. 8 Photograph of the PIV setup. Note that the wave gauge is located behind the vertical 416 laser sheet. 

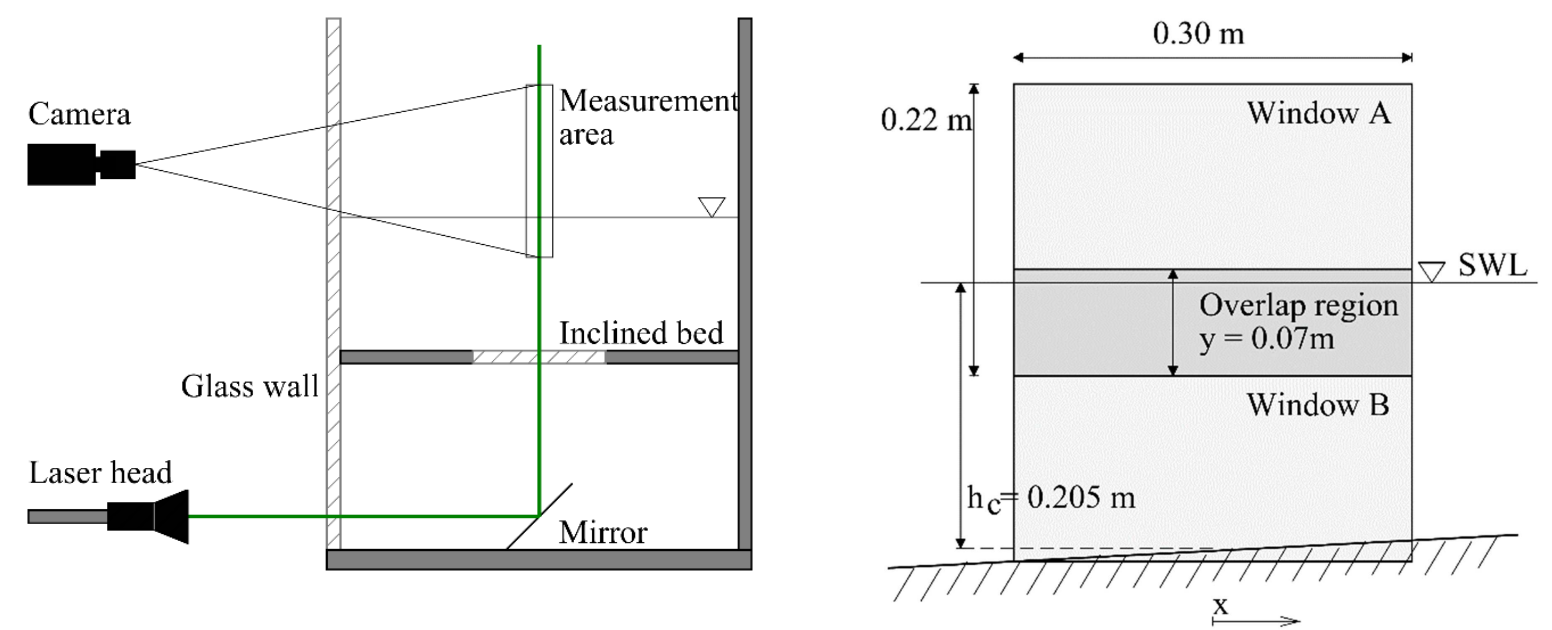

418 Fig. 9 a) Cross-sectional view of the wave flume at the PIV/PTV measurement area. The laser 419 sheet reflected by a mirror at the bottom of the flume and passed through a window in the 420 inclined, smooth bed. b) Field of view of the PIV/PTV measurement area with the two over421 lapping PIV windows, labelled window A and window $B$.

422 A PIV algorithm computed the velocities as outlined in (Vested et al., 2018b). To validate the 423 velocity measurements, the velocity profiles were compared to LDV measurements. The 424 LDV measurements were performed using a one-component Dantec Dynamics LDV system 425 in backward scatter mode with a $514.5 \mathrm{~nm}$ laser. The LDV probe was mounted on a traverse 426 system that allowed for vertical traverse movements with an accuracy of $0.1 \mathrm{~mm}$. After each 427 measurement, the measurement volume was moved vertically. Measurements were made for $42850 \mathrm{~s}$ at 9 vertical positions between the laboratory bed and the wave trough at $0.005 \mathrm{~m}, 0.025$ $429 \mathrm{~m}, 0.045 \mathrm{~m}, 0.065 \mathrm{~m}, 0.085 \mathrm{~m}, 0.105 \mathrm{~m}, 0.125 \mathrm{~m}, 0.0145 \mathrm{~m}$ and $0.165 \mathrm{~m}$. After data collec430 tion, the LDV measurements were resampled to a temporal resolution of $300 \mathrm{~Hz}$ to obtain 431 equidistant time.

433 Fig. 10 compares the profile of horizontal velocity from LDV and from PIV measured from 434 the bed at to $0.02 \mathrm{~m}$ below still water level at eight phases of the wave period. The compari435 son shows a high level of agreement between PIV and LDV measurements. 

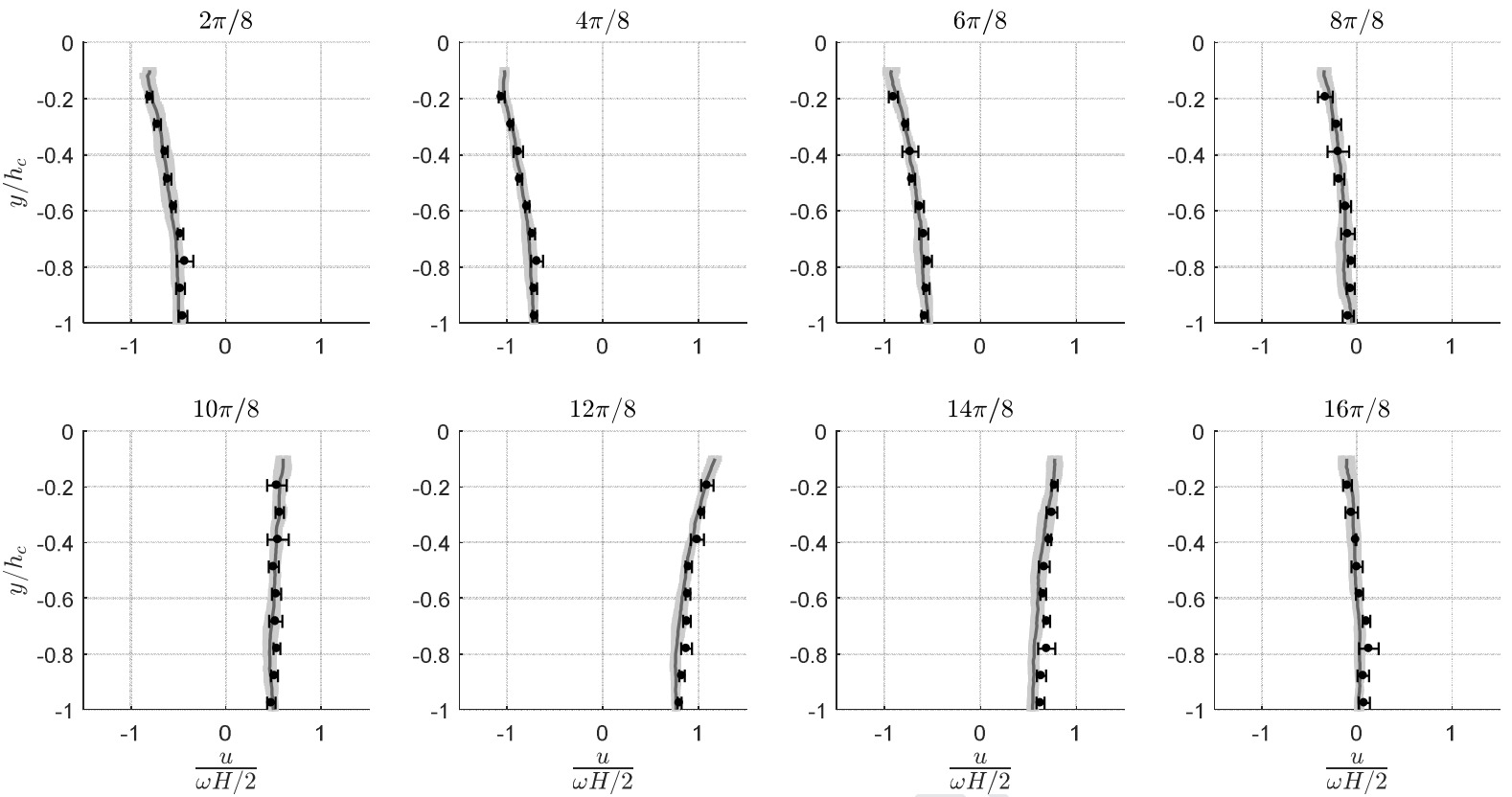

Fig. 10 Profiles of horizontal velocity measured from PIV (gray) and LDV (black) from the

bed to $0.02 \mathrm{~m}$ below SWL. Wave period $T=1.0 \mathrm{~s}$, wave height $H=0.033 \mathrm{~m}$ (test 1 ). The shad-

ed areas represent individual PIV runs. The error bars on the LDV results represent the

standard deviation.

The algorithms used to assess the velocities were optimized for the specific measurements and are described under the relevant sections. Local accelerations were computed from the measured velocity through a right-sided finite difference scheme:

$\frac{\partial u_{i}\left(x, y, t_{i}\right)}{\partial t} \cong \frac{u_{i}\left(x, y, t_{i+1}\right)-u_{i}\left(x, y, t_{i}\right)}{\Delta t}$

in which $\Delta t$ is the time between samples, which for this set-up corresponded to about $0.01 \mathrm{~s}$.

Spatial derivatives were computed through a second order central difference scheme:

$$
\begin{aligned}
& \frac{\partial u_{i}\left(x_{i}, y, t\right)}{\partial x} \cong \frac{u_{i}\left(x_{i+1}, y, t\right)-u_{i}\left(x_{i-1}, y, t\right)}{2 \Delta x} \\
& \frac{\partial u_{i}\left(x, y_{i}, t\right)}{\partial y} \cong \frac{u_{i}\left(x, y_{i+1}, t\right)-u_{i}\left(x, y_{i-1}, t\right)}{2 \Delta y}
\end{aligned}
$$

448 in which $\Delta x$ and $\Delta y$ are the spatial distance of measurent points in the PIV window and de-

449 pend on the spatial resolution of the velocity field. The time increment $\Delta t$ is the time between 450 subsequent velocity measurements. As the velocities were sampled at $96 \mathrm{~Hz}$, the time incre- 
451

452

453

454

455

456

457

458

459

460

461

462

463

464

465

466

467

468

469

470

ment was $\Delta t \cong 0.01 \mathrm{~s}$. The velocity was filtered at $5 \mathrm{~Hz}$ before computing the acceleration to obtain a smooth acceleration signal.

Fig. 11 shows profiles of local horizontal acceleration for wave test 1 with wave period $\mathrm{T}=$ 1.0s and wave height $\mathrm{H}=0.033 \mathrm{~m}$. A good agreement between PIV and LDV results is seen. The comparison between the local acceleration measured through PIV and LDV indicate that the PIV sampled at $96 \mathrm{~Hz}$ was adequate for obtaining accelerations for laboratory waves.
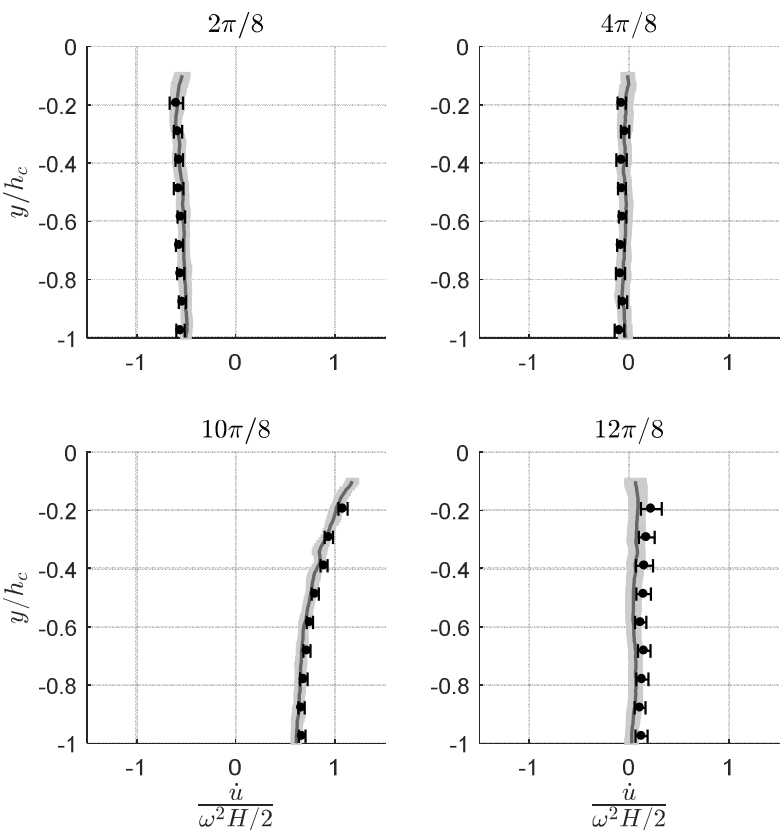
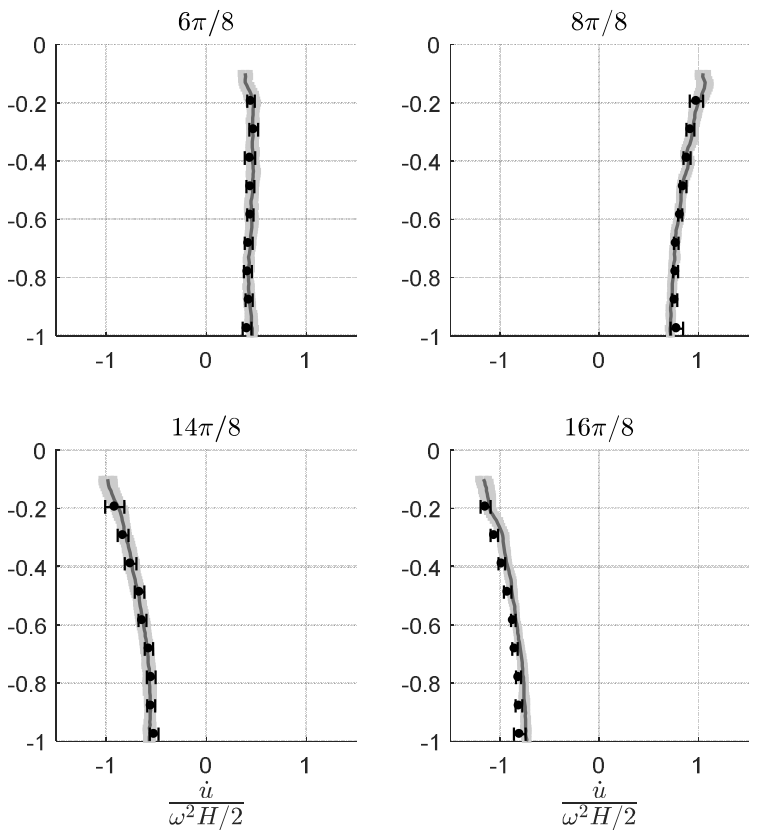

Fig. 11 Profiles of local horizontal acceleration, measured by PIV (grey) and LDV (black) from the bed to $0.02 \mathrm{~m}$ below SWL. Wave period $T=1.0 \mathrm{~s}$, wave height $H=0.033 \mathrm{~m}$ (test 1 ). The shaded areas represent individual PIV runs. The error bars on the LDV results represent the standard deviation.

\section{Wave loads}

\subsection{Time series of wave loads}

The wave loads were measured at four sections along the cylinder and the total load was obtained from the sum of local contributions. Fig. 12 shows the surface elevation and the total wave load for test conditions 1 and 4 . The wave period was $T=1.0 \mathrm{~s}$ in both tests, while the wave height was $H=0.033 \mathrm{~m}$ and $H=0.100 \mathrm{~m}$ in test 1 and test 4 , respectively. Test 4 therefore represents a steeper wave condition relative to test 1 . The surface elevation in test 1 ap- 
471

472

473

474

475

476

477

478

479

480

481

482

483

484

485

486

487

488

489

490

491

492

493

494

495

496

497

pears close to sinusoidal in shape, while test 4 has a wider trough and a narrower crest as well as a steeper wave front. The maximum wave load was $1.4 \mathrm{~N}$ in Test 1 and $4.7 \mathrm{~N}$ in Test 4 . In both wave conditions, the maximum wave load appeared close to maximum of the surface elevation gradient. For these two test cases, the KC-number was smaller than five and therefore the inertia force dominated.

The force obtained from Morison's equation using stream function theory is included for comparison. For slender structures, a Morison force model is often used to estimate the wave forces. The wave force is found as:

$$
F(t)=\frac{1}{2} \rho C_{D} D u(t)|u(t)|+\rho C_{M} A \frac{d u(t)}{d t}
$$

$\rho$ is the density of water, $D$ is the diameter of the cylinder, $u$ is the velocity, $A$ is the crosssectional area of the cylinder and $C_{D}$ and $C_{M}$ are the drag and inertia coefficients, respectively. The total force is obtained from integration over the vertical coordinate $y$, using the undisturbed wave kinematics. In the following comparisons no attempt has been made to include effects of for instance diffraction or other phenomenon at the free surface The stream function estimated the wave kinematics and to integrate eqs. ( 4.1) force coefficients from (Sarpkaya, 1976a), $C_{M}=2.0$ and $C_{D}=1.0$, was used. Even though the force coefficients are generally known to vary with the $\mathrm{KC}$ and $\mathrm{Re}$, they were assumed constant for the first rough comparison between measured forces and calculated forces. For the comparisons in the following Test 1 and 4 the KC number was 1.7 and 5, respectively. The Re was 11000 and 34000, respectively. In this range of $\mathrm{KC}$ and $\mathrm{Re}$ the chosen force coefficients are believed to be representative with an accuracy of a few percent. In for instance Fig. 26 we estimated the inertia force coefficient based on measured wave kinematics, which further supported choice of coefficients.

For test 1, see Fig. 12, the stream function estimate of total wave load agrees well with the measured wave loads. For test 4 , stream function theory overestimate the maximum load but still succeeds in capturing the shape of the load time series to some extent. (1) 

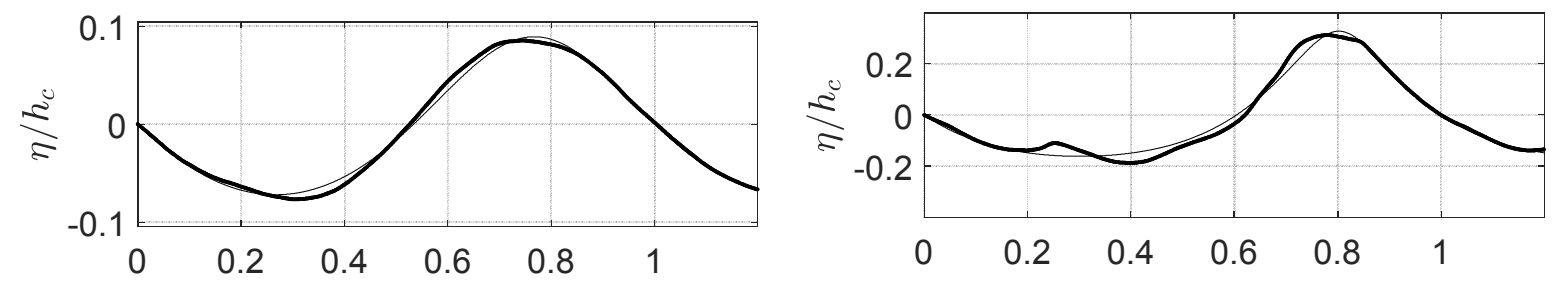

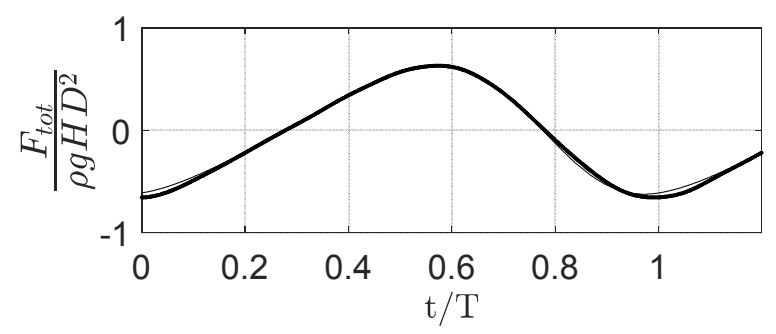

a)

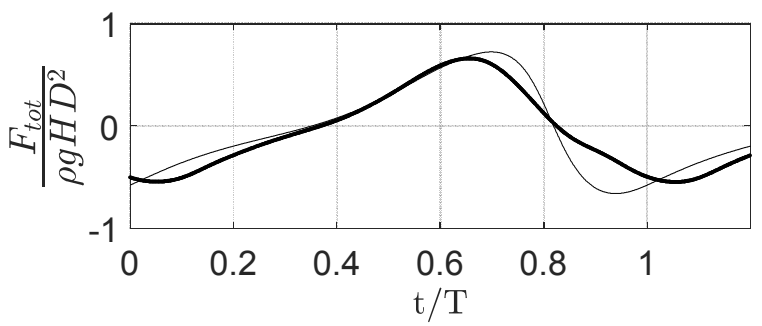

b)

Fig. 12 Surface elevation [m] and total wave load [N]. Black full line: Measured data, thin line: Stream function. (a) Test 1, wave period $T=1.0 \mathrm{~s}$, wave height $H=0.033 \mathrm{~m}$. (b) Test 4, wave period $T=1.0 \mathrm{~s}$, wave height $H=0.100 \mathrm{~m}$.

Fig. 13a and Fig. 13b show the surface elevation and the time series of wave loads on individual sections for test 1 and test 4 . The incoming waves induced wave loads on the three lower sections. For both wave conditions, the cylinder section 4 was unaffected by the waves except for the passage of the wave crest in test 4 , with only a small positive load. Furthermore, the time at which the wave load was maximum at section 3 came later relative to section 1. Conversely, the local force minimum was leading at section 3 relative to section 1.

Fig. $13 \mathrm{~b}$ shows the measured wave loads for test 4 , which had the same wave period as Test 1 but a larger wave height. During this wave test, only the wave load at section 1 appeared close to sinusoidal shaped, while at sections 2 and 3 the wave loads were not sinusoidal shaped. The reason for the difference between the wave loads at individual sections can be attributed to higher order contributions in the wave kinematics, which are expected to be more pronounced close to the free surface and smaller close to the bed. Stream function theory estimated of surface elevation and local wave loads estimated from the Morison equation are included for comparison. The combination of stream function theory and Morison equation showed a good agreement except for at section 3 in test 4, in which the stream function force overestimated the maximum force. 

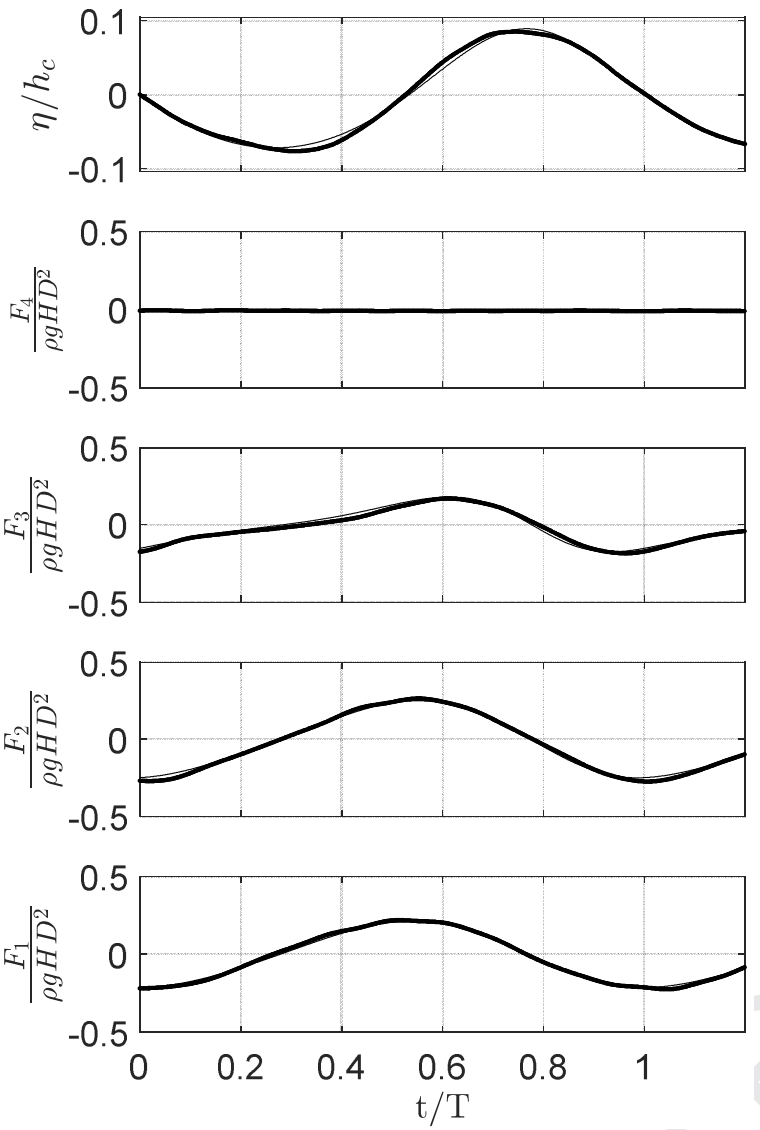

a)
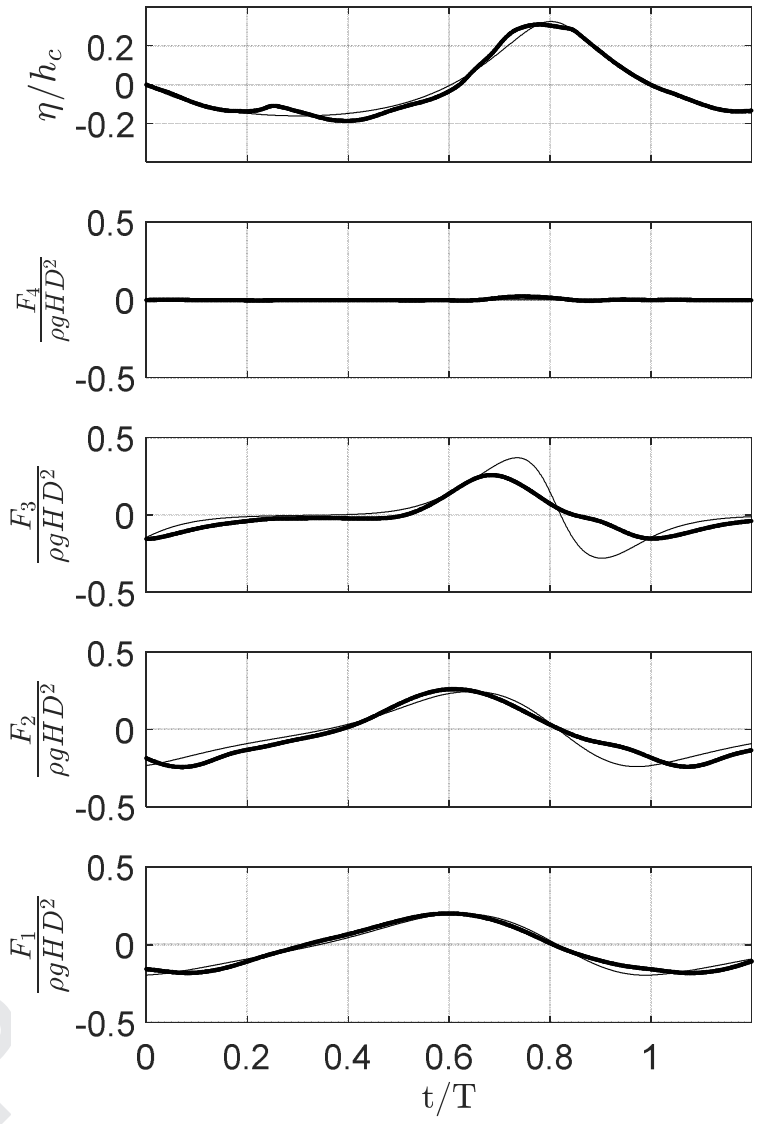

b)

518 Fig. 13 Time series of surface elevation and measured wave load at section 1, 2, 3 and 4. (a)

Time series of wave test 1 , wave period $T=1.0 \mathrm{~s}$ and wave height $H=0.033 \mathrm{~m}(\boldsymbol{b})$ Time series of wave test 4, wave period $T=1.0 \mathrm{~s}$ and wave height $H=0.100 \mathrm{~m}$.

\subsubsection{Time of peak load}

522 As shown above the time of maximum force was different on the individual sections in case 1 and 4 . The time of maximum force was different in case 1 and 4 because of the different con-

524 tribution of the drag and inertia forces. For test 4, the wave height was higher and then the 525 drag contribution are expected to increase. Indeed, a forward shift of the total force towards

526 the wave crest was noticed. In this section, we analyse the time maximum and minimum force on the individual sections, hereafter denoted $t_{F \max }$ and $t_{F m i n}$, in more detail.

Since $t_{F \max }$ depended on the shape of the force time series, we studied the dependence on the

530 Ursell number, $U r$, defined in eqs (2.7). The Ursell number, $U r$, is derived from Stokes wave

531 expansion in the shallow water limit and thus assumes that $L \gg h$. In these experiments

$5320.06<h / L<0.17$ and the assumption holds albeit with some precaution. For long waves 
$533(L \gg h)$ with small Ursell number, the first order contribution to the dynamics dominate, i.e.

534 the wave can be described by linear theory, as according to (Dingemans, 1997). Otherwise, a

535 higher order theory is needed to describe the waves.

537 Fig. 14 shows the time of maximum force $t_{F \max }$ for each section relative to the wave period $T$ 538 as a function of Ursell number. The figure shows that $t_{\text {Fmax }}$ increased with the Ursell num-

539 ber. Furthermore, we observed a weak tendency of increasing $t_{F \max }$ from lower positioned 540 sections to sections closer to the surface and therefore the largest maximum force was closest 541 to the surface. The figure also show that the difference in peak time between the sections de542 creased with the Ursell number. Thus, for larger Ursell number, the sections experienced 543 maximum forces almost at the same time. For instance, for smaller Ursell numbers, $U r \leq 50$, 544 the difference in $t_{F \max } / T$ between section 1 and section 4 was around 0.15 while for $U r \approx$ 545200 , the difference was around 0.06 . This may be explained by the difference in wave form 546 with Ursell number. A large Ursell number describe a wave condition with a narrow crest and 547 wide trough. Accordingly, for larger Ursell numbers, the time span between maximum forces 548 on different cylinder sections was narrower.

550 In Fig. 15 shows the time $t_{F \min }$ for the minimum wave load on four cylindrical sections. The 551 measured values of $t_{F m i n}$ showed that the minimum force arrived earlier as the Ursell number 552 increases for the same reason as the maximum force arrived later due to a narrower wave 553 crest. A large degree of scatter was seen for all the sections. Therefore, no general trend in $554 t_{F m i n}$ between the sections was observed.

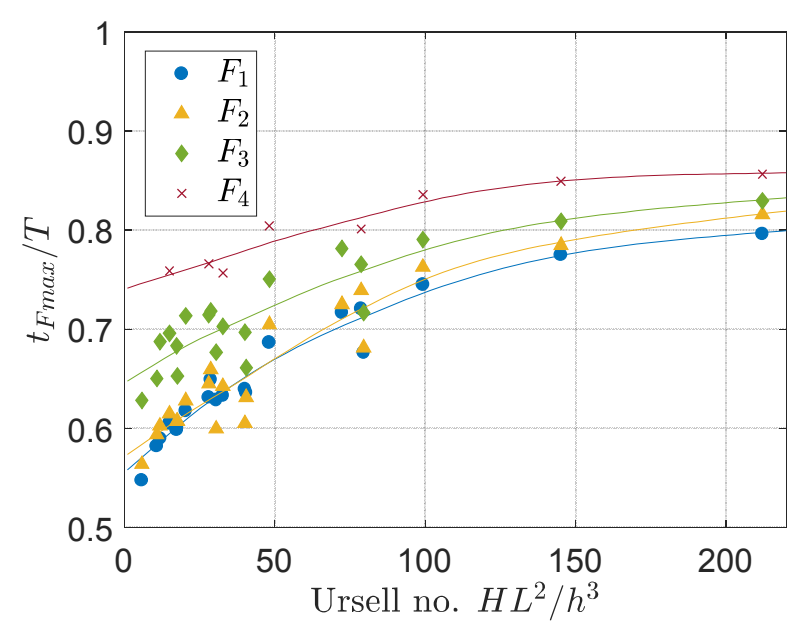

Fig. 14 Relative time of maximum load $t_{\text {Fmax }} / T$ at individual sections, with trend lines. 
558 Overall, these results shows that the time of peak load is almost simultaneous for wave condi-

559 tions with high Ursell number. For wave conditions with small Ursell number, however, the

560 maximum force occurs later at the section close to the free surface than at the section closer to 561 the bed.

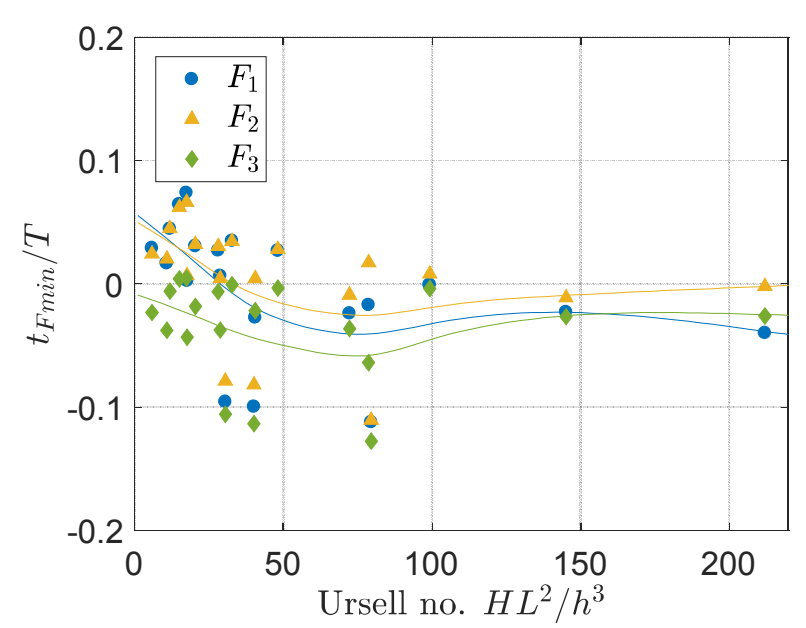

Fig. 15 Relative time of minimum load $t_{F m i n} / T$ at individual sections, with trend lines.

\section{$564 \quad 4.2$ Force harmonics}

565 (Kristiansen and Faltinsen, 2017) presented a comprehensive study on force harmonics de566 rived from time series of wave forces on a vertical circular cylinder. Their experimental re-

567 sults were compared to the theory by (Faltinsen et al., 1995), also known as the FNV theory

568 for wave loads. In their study the total load signal on a vertical circular cylinder was decom-

569 posed into harmonic contributions, which individually were compared to calculations with the 570 FNV theory.

572 The data available for the fourth section from the sloping bottom was to scarce to include in 573 the analyses. To be able to compare the force harmonics directly the forces were adjusted for 574 the wetted height of the cylindrical sections.

$$
F_{i}^{\text {mod }}=\frac{L C}{\Delta z_{\text {wet }}} F_{i}^{\text {meas }}
$$

575 where $F_{i}^{\text {mod }}$ is the modified force for section $i, L C$ is the total height of the section, $\Delta z_{w e t}$ is 576 the height of the wetted/submerged part of the section, and $F_{i}^{\text {meas }}$ the measured force for sec577 tion $i$. The analyses included data where at least $1 \mathrm{~cm}$ of the $8 \mathrm{~cm}$ high sections was sub578 merged. The first two section from the bottom was submerged in all cases, while typically 
half of section 3 was submerged at maximum forces. This procedure can also seen as a way of finding the force per length.

Fig. 17 and Fig. 18 shows examples of force measurements decomposed into harmonics. The 583 decomposition was made directly from and overdetermined system as:

$$
F_{i}(t)=\sum_{j=1}^{m} A_{i}^{j} \cos (j \omega t)+B_{i}^{j} \sin (j \omega t)
$$

584

where $F_{i}(t)$ is the force on cylinder section $i$, at time t. The angular frequency, $\omega$, is already known from Tab. 1. $\mathrm{m}$ is the number of harmonics that should be included in the force harmonics analyses. $A_{i}^{j}$ and $B_{i}^{j}$ are amplitudes for harmonic $j$. As we tested the system for the first three harmonics, $m=3$, the number of unknowns is 6 . The number of measured time steps was much larger, which results in an overdetermined system that it is straight forward to solve the system with a least-square methodology. The absolute value of each harmonic is:

$$
F_{i}^{j}=\sqrt{\left(A_{i}^{j}\right)^{2}+\left(B_{i}^{j}\right)^{2}}
$$

The analyses included only force measurements found at time steps where at least $1 \mathrm{~cm}$ of cylinder section was submerged. This means that sections at the free surface had fewer time steps included in the analyses. The use of the above method showed to be robust even for sections that shifted between wet and dry. Alternatively the harmonics can be found from narrow-band filters around each frequency as used in for instance (Kristiansen and Faltinsen, 2017), which works well as long as either the full force or forces on fully submerged sections are analysed.

Fig. 16 shows the contribution of first, second and third harmonics to the measured wave load. The contribution from each harmonic was estimated from the overdetermined system above. The figure shows that the second harmonics were rather strong in test 4 at the third section. 

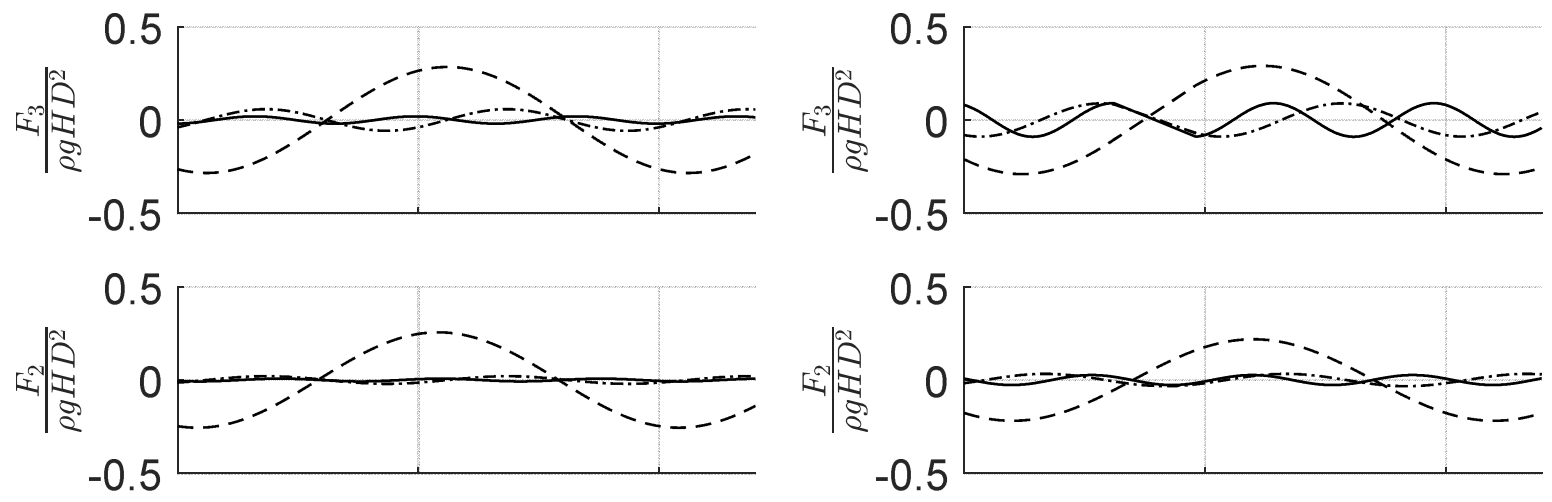

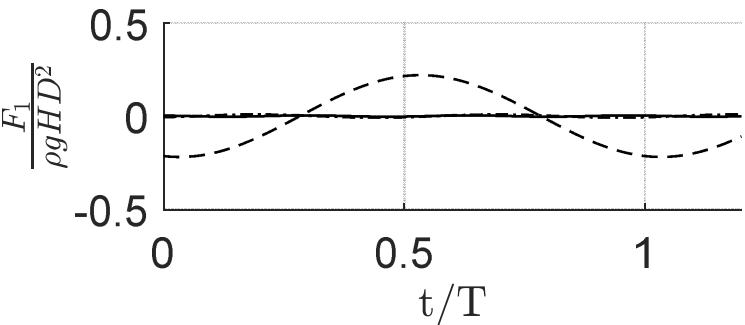

a)

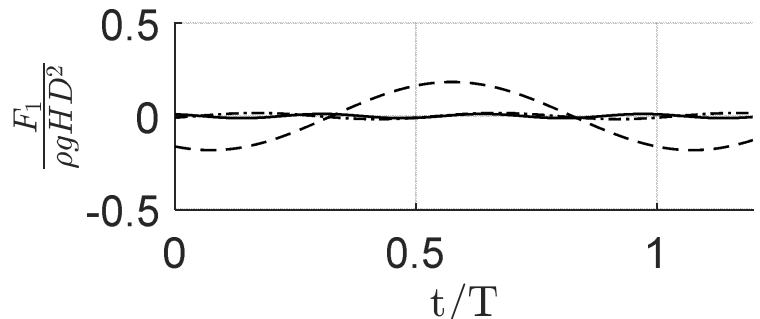

b)

602 Fig. 16 First, second and third harmonics of the wave loads at section 1, 2 and 3. Dashed line 603 is first harmonics, dashed-dotted line is second harmonics, full line is third harmonics. (a) 604 test $1(b)$ test 4.

F1

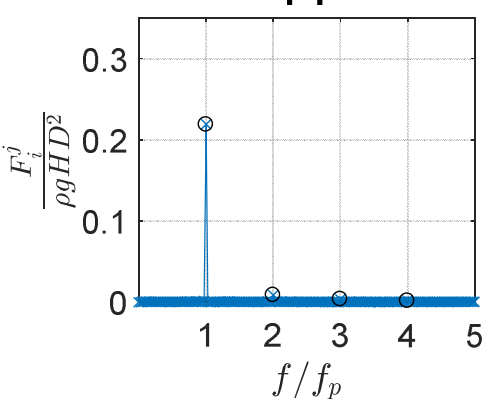

F2

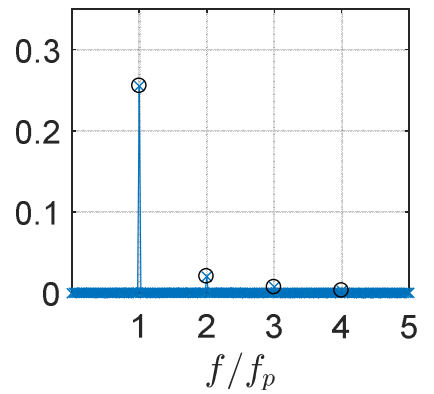

F3

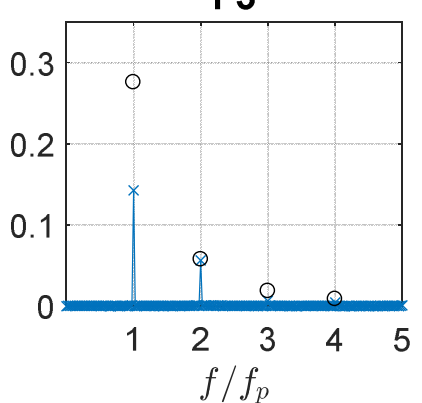

606

607

608

609

610

611

612

613

614

Fig. 17 Spectral amplitudes of force harmonics for section 1 through 4 for test 1. ०:direct method, $\mathbf{x}$ : spectral analyses.

Fig. 17 shows the amplitudes of the harmonics of the measured force at each section in test 1 . At sections 1 and 2 the spectra were largely dominated by the first harmonic, while at section 3 the second harmonic is about half of the first harmonic. The same spectrum analysis on test 4 is shown in Fig. 18. At sections 1 and 2, the first order contribution was still dominant and the peak height of second and third harmonics were less than $15 \%$ of the first harmonic. At section 3 , however, the second harmonic was more than $2 / 3$ of the first harmonic. Therefore, second order harmonics were important when describing the wave loads close to the free sur- 
615 face for the wave conditions in test 4. The spectrum analysis also showed that the higher order contributions entrained further down into the water column in test 4 relative to test 1 , since at section 2 the higher harmonics was $10-15 \%$ of the first harmonic.

F1

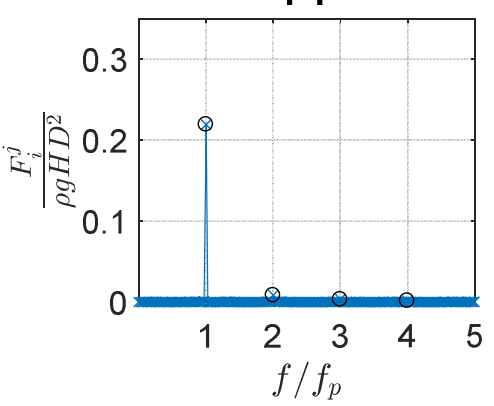

F2

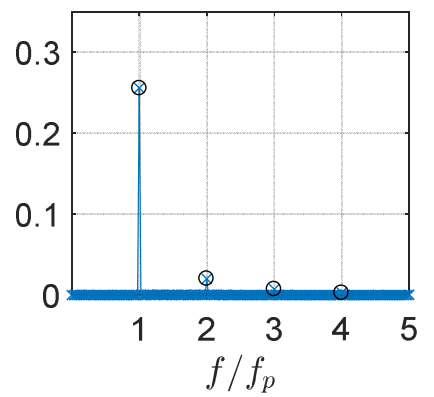

F3

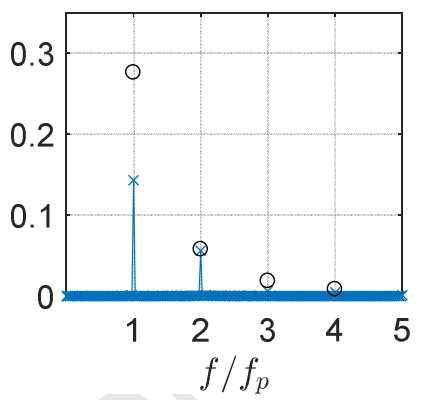

619 Fig. 18 Spectral components of force harmonics for section 1 through 4 for test 4 . $\circ:$ direct

620 method, $\times$ : spectral analyses.

621 The decomposition of the forces into force harmonics was conducted for all 20 test cases for

622 both the full force as well as forces on individual cylinder sections. Fig. 19 shows the decom-

623 position for the full force that qualitatively can be compared to findings in (Kristiansen and

624 Faltinsen, 2017) for their case with $h / a=5.51$ on a horizontal bottom. In our experiments, the

625 ratio $h / a$ was 5.13 with sloping bed of 1:25. Despite the differences with the sloping bed, the

626 two sets of data shows approximately the same behaviour. For instance (Kristiansen and

627 Faltinsen, 2017) case with $k a=0.182$ and gives a $k h=1.00$, which is close to first row of

628 panels in Fig. 19. For a wave steepness of $\frac{H}{L}=0.05$ their first and second harmonics were

629 approximately $\frac{F_{t o t}^{1}}{\rho g D^{3}}=0.5$, and $\frac{F_{t o t}^{2}}{\rho g D^{3}}=0.1$, while ours where $\frac{F_{t o t}^{1}}{\rho g D^{3}}=0.44$, and $\frac{F_{t o t}^{2}}{\rho g D^{3}}=0.11$.

630 The differences for the first order harmonic can be related to different relative water depth

$631 h / a$. This affect appears to be linear for the first order harmonic and we multiply our result

632 with the ratio between the two relative water depth of 1.075 we get, $1.075 \frac{F_{t o t}^{1}}{\rho g D^{3}}=0.47$, with

633 the differences in the experimental set up in mind this indicates the same level. 

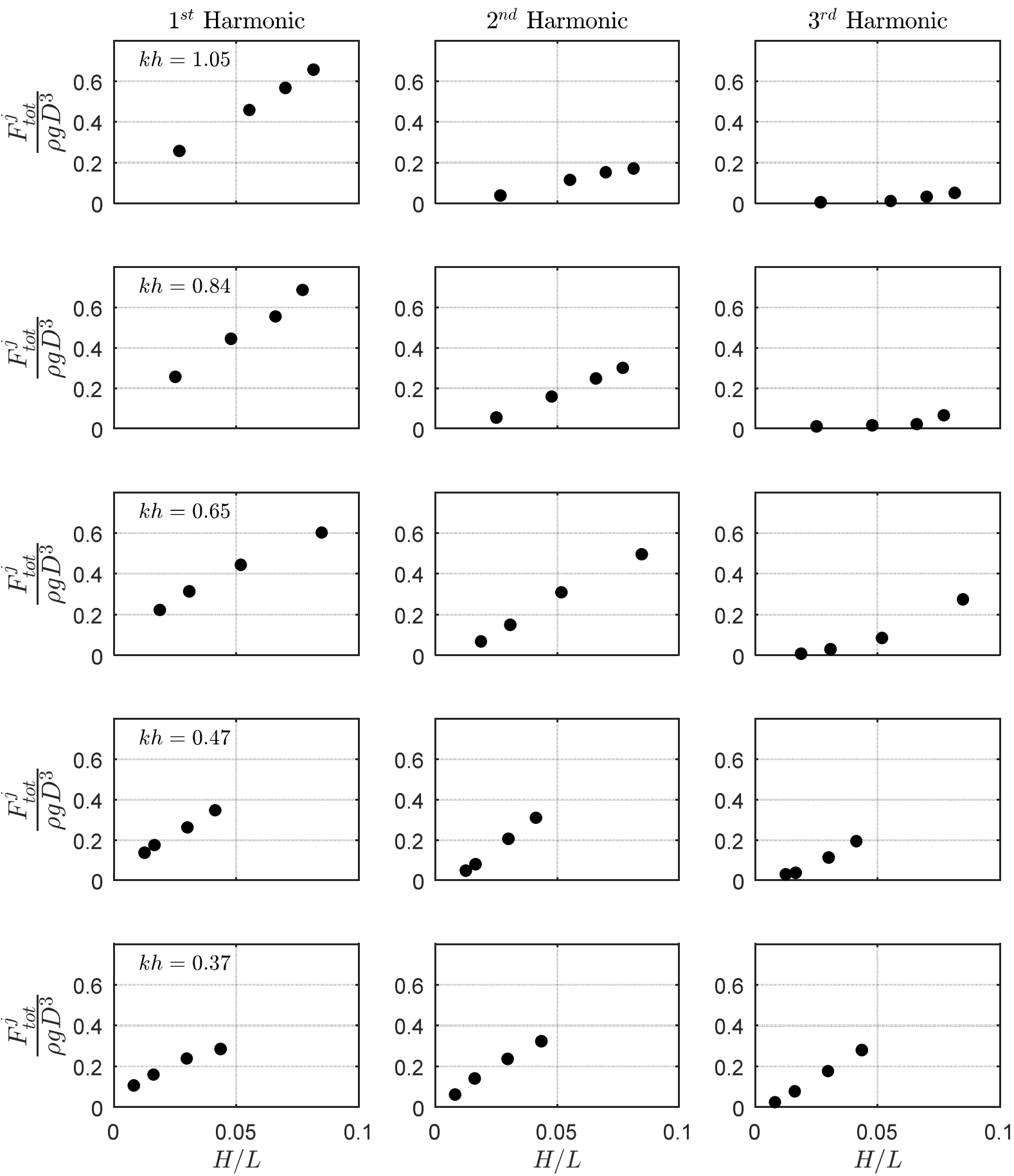

636 Fig. 19 Force harmonics for total force as a function of wave steepness $H / L$

637 The relationship between the force harmonics and wave steepness was very similar to

638 (Kristiansen and Faltinsen, 2017). However, their forces starts to decline for a ratio of the

639 wave height and depth $\frac{H}{h} \sim 0.5$ to 0.6 , which corresponds well with the upper practical limit

640 for wave breaking in a very flat bottomed wave tank $\frac{H}{h}=0.55$ suggested by (Nelson, 1994) 
641 based on a large number of experiments reported in the literature. In our study the ratio of

642 wave height over depth along the plane bed was typically $\frac{H}{h_{A}}<0.4$, and the waves did not

643 break before they reached the slope. For waves on a slope waves start to break when the rela-

644 tive wave height is around 0.8. This means that our waves broke later, which explains why we

645 did not observe the decline in the force harmonics for increasing wave steepness.

646

647 Fig. 20 shows the force measurements decomposed into force harmonics for each of the first

648 three sections. The data available for the fourth section from the bed was too scarce to include

649 in the analyses. For the largest wave number, $k h=1.05$, we found that the first force har-

650 monic contribution from the third section tend to increase slightly non-linear with the wave

651 steepness, while the other two was close to linear. The first force harmonic for the three sec-

652 tion were relatively close to each other compared to the case for the second force harmonic.

653 Here the contribution to the third section was up 5 times larger than on the first section. Even

654 compared to the first force harmonic the contribution from the third cylinder section was sub-

655 stantial. The differences in the contribution from the three sections to the third force harmonic

656 was less pronounced compared to the second force harmonics. 

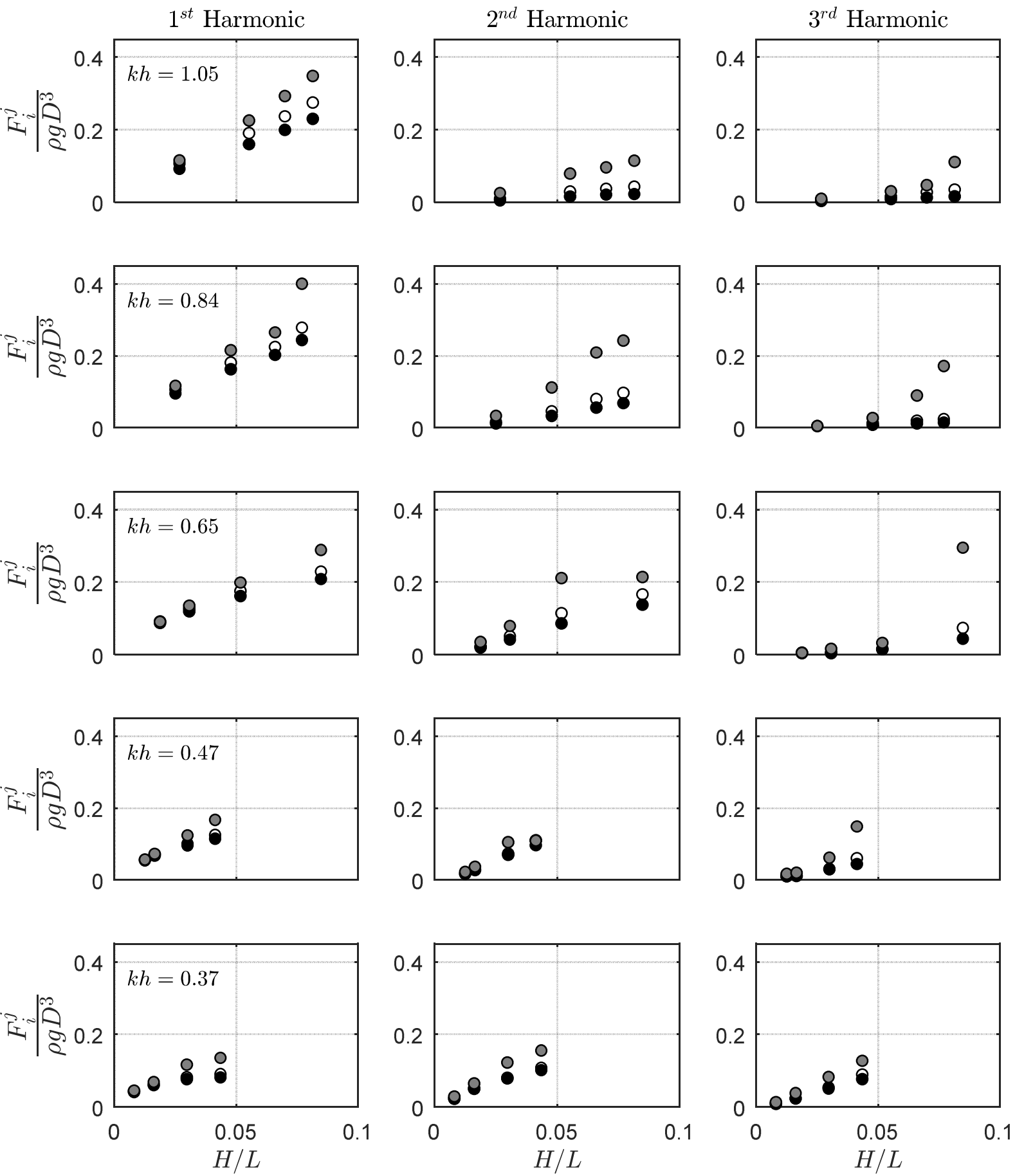
$H / L$

659 Fig. 20 Force harmonics for the three first section from bottom. Section 1:•, section 2: ○, 660 section 3: •, as a function of wave steepness $H / L$.

661 For decreasing wave number, $k h$, from 1.05 towards 0.37 the second force harmonic gave 662 more pronounced contribution to the force. This was also clear from Fig. 19 where the contri663 bution from the second force harmonic was of approximately the same size as the contribu664 tions from the first force harmonic. Even in this case the contribution from the third cylindri- 
665 cal section was substantial larger than for the lower two sections. The significance of the third 666 force harmonic seemed less pronounced, but up to around half of the second force harmonic.

667 The trend was not found to be of same clear tendency as found for the first and second force 668 harmonics. Note that the waves broke after the passage of the vertical circular cylinder, which 669 might partly explain the difficulties in finding a clearer general trend in the third force har670 monic as the force time series could be affected by fluctuating flow velocities coming from 671 turbulence produced in the breaking process. In some cases, for instance for $k h=0.65$, the 672 wave breaking process appeared also to affect the second harmonic for the upper third section.

\subsection{Wave load distribution}

675 Fig. 21 shows the force distribution of wave test 1 for eight phases of the wave cycle. Each marker in the phase plot represents the ensemble mean force of 40 consecutive waves. The standard deviation of the wave load for the 40 consecutive waves is smaller than the marker size for the wave conditions in test 1 . The time was set to 0 at zero-down crossing as shown in Fig. 12. Observing the force distribution at $\omega t=\pi / 8$ through $4 \pi / 8$ the force was negative before crossing zero around $\omega t=4 \pi / 8$ from when the force was positive until $\omega t=13 \pi / 8$. The total force was maximum around $\omega t=10 \pi / 8$. The measured force distribution was compared to calculations with stream function theory with constant force coefficients from (Sarpkaya, 1976a). Observing the force at section 1 and 2 the measured wave loads agreed well with the calculations. At section 3, the measured wave load is out of phase with the stream function result. This is especially evident as the total wave force increases at $\omega t=$ $6 \pi / 8$ through $\omega t=8 \pi / 8$.

688 Fig. 22 shows the force distribution for test 4 for eight phases of the wave cycle. The wave period was $\mathrm{T}=1.0 \mathrm{~s}$ and the wave height was $\mathrm{H}=0.100 \mathrm{~m}$. The variation between consecutive waves increased relative to test 1 and error bars represent the standard deviation of the measured force. The stream function wave load captures the measured wave load to some extent at section 1 and 2. At section 3, however, the stream function distribution largely fails to represent the measured force. At the maximum force around $\omega t=10 \pi / 8$, however, the agreement between the measured and calculated force distribution was good. 

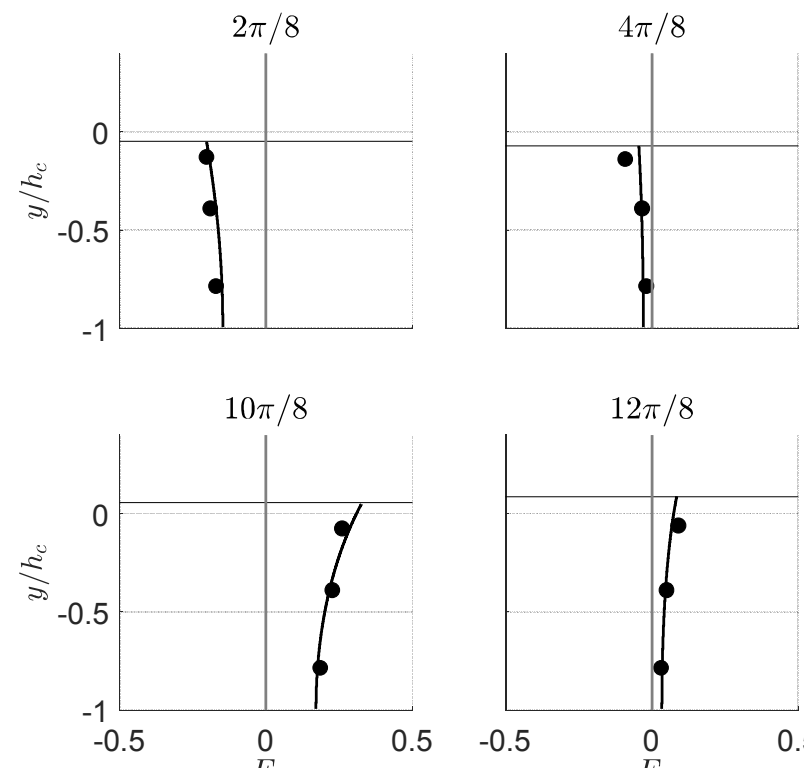

696

697

698 Fig. 21 Force distribution, wave period $T=1.0$ s and wave height $H=0.034 m$ (test 1). Black 699
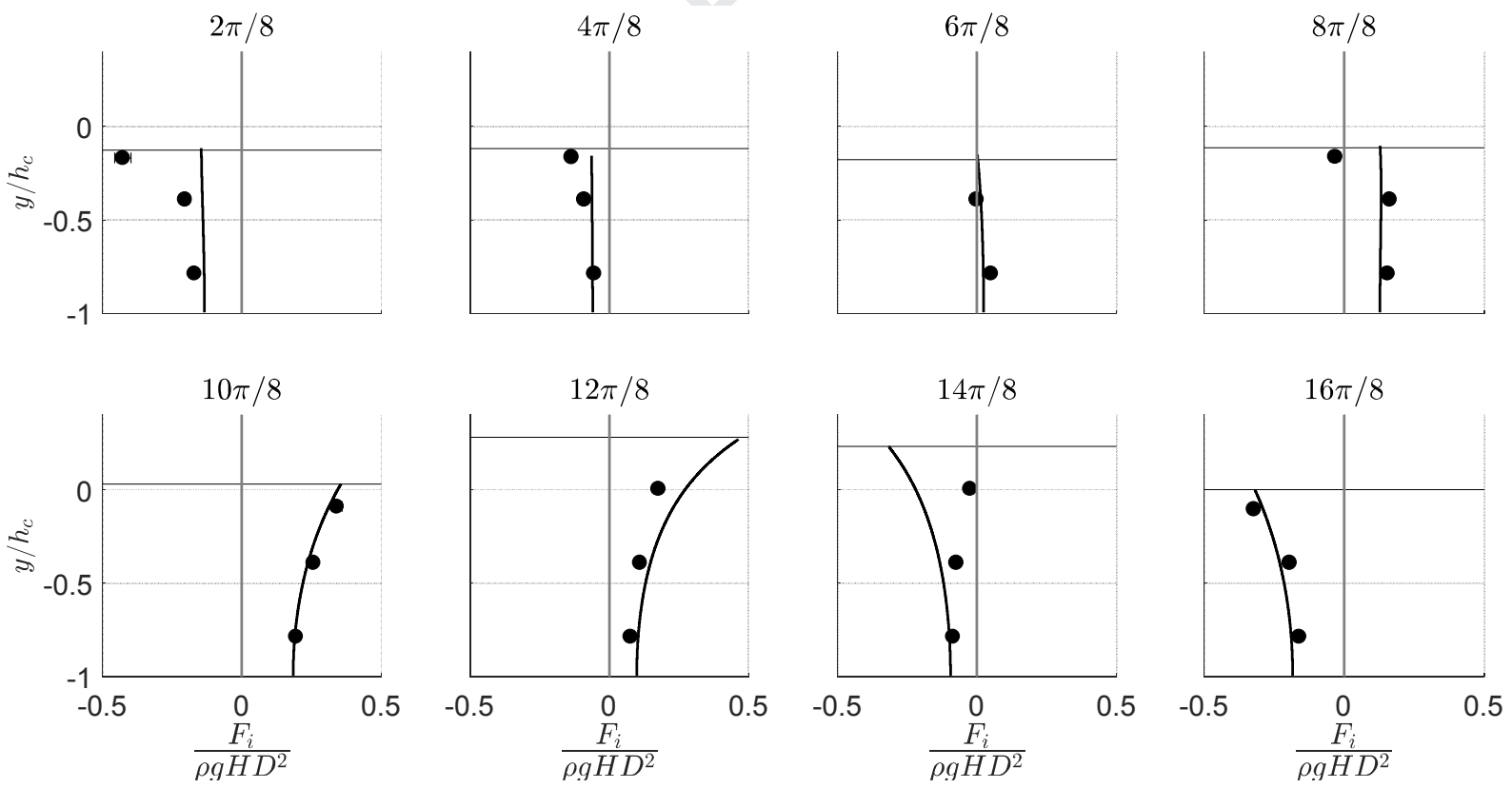

701

Fig. 22 Force distribution, wave period $T=1.0$ s and wave height $H=0.098 m$ (test 4). Black 702
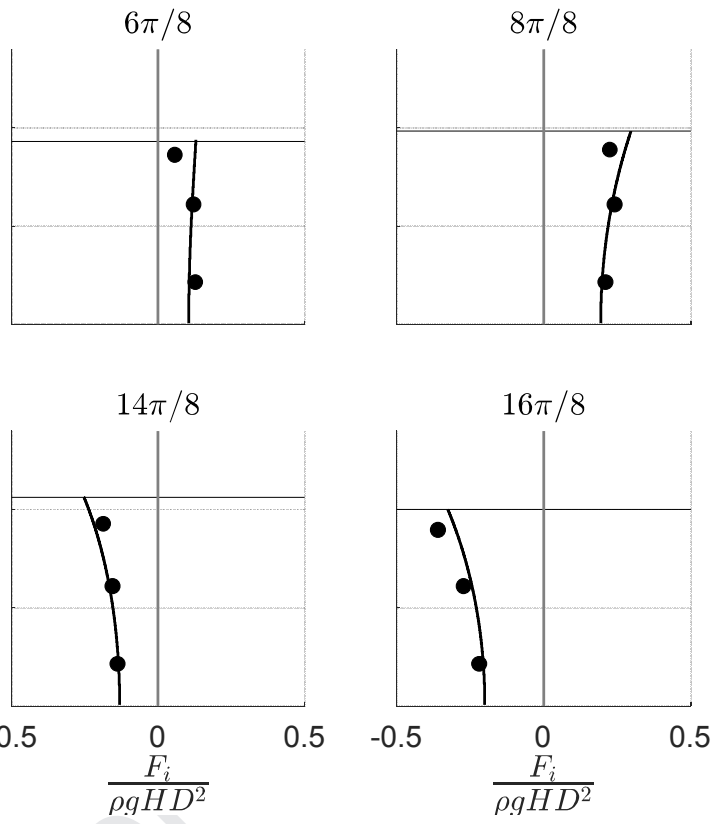

. 

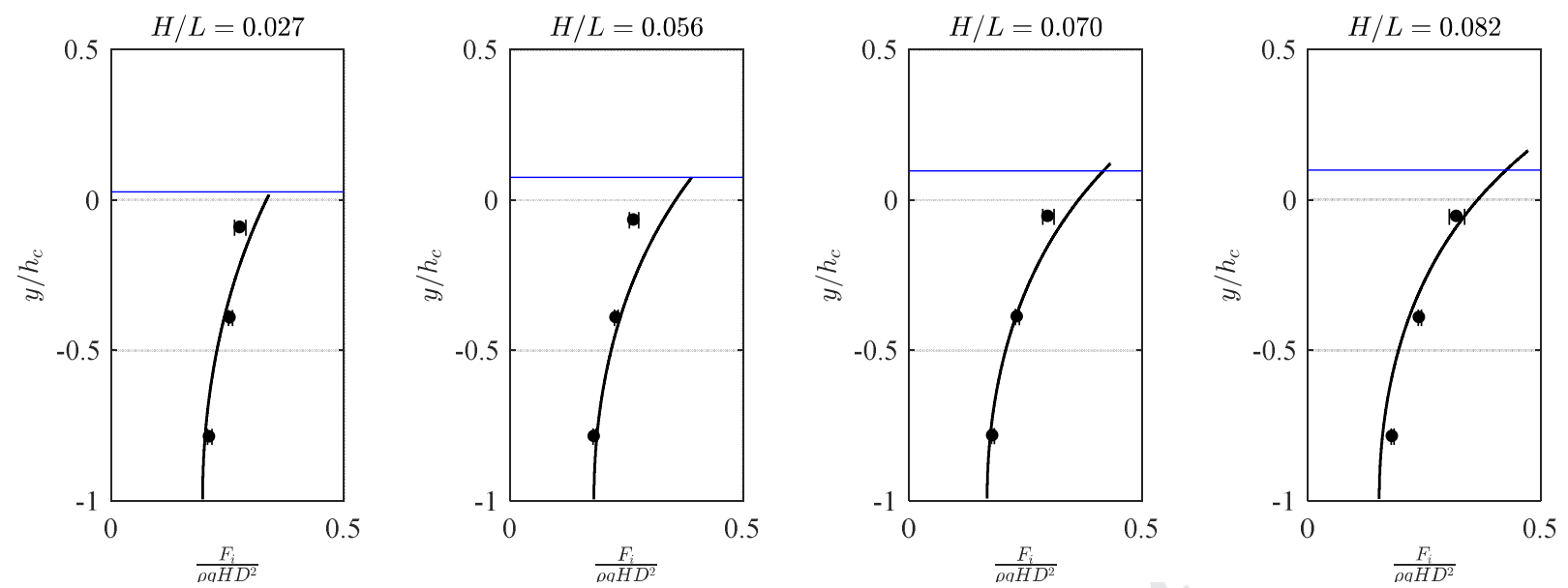

703

704

705

706

707

708

709

710

711

712

713

714

715

716

717

Fig. 23 Force distribution at maximum total force for four wave cases with $\mathrm{kh}=1.05$. Full line: Stream function+ Morison force. Markers measured force.

The force distribution is plotted at the time instant when the total wave load is maximum in Fig. 23. The wave steepness varied from $\mathrm{H} / \mathrm{L}=0.03$ to $\mathrm{H} / \mathrm{L}=0.08$. The figure shows that the force increased towards the free surface. The steeper the wave, the larger the difference in wave load between bottom and top. The calculated distributions tended to estimate higher wave load on section 3 regardless of the wave steepness compared to the measured force distribution.

\section{Wave kinematics and force coefficients}

\subsection{Kinematics}

Fig. 24 shows the measured horizontal velocity profile of Test 1 . The velocity profile is shown at eight phases of the wave period along with stream function velocity. A good agreement between the measured velocity and stream function was observed. Fig. 25 shows the local acceleration $\partial u / \partial t$ computed from the measured velocities. In general a good agreement between the measured kinematics and the stream function was observed for all phases of the cycle. A weak tendency showed a larger variation of the acceleration over the depth in the measurements compared to the stream function theory. 
723
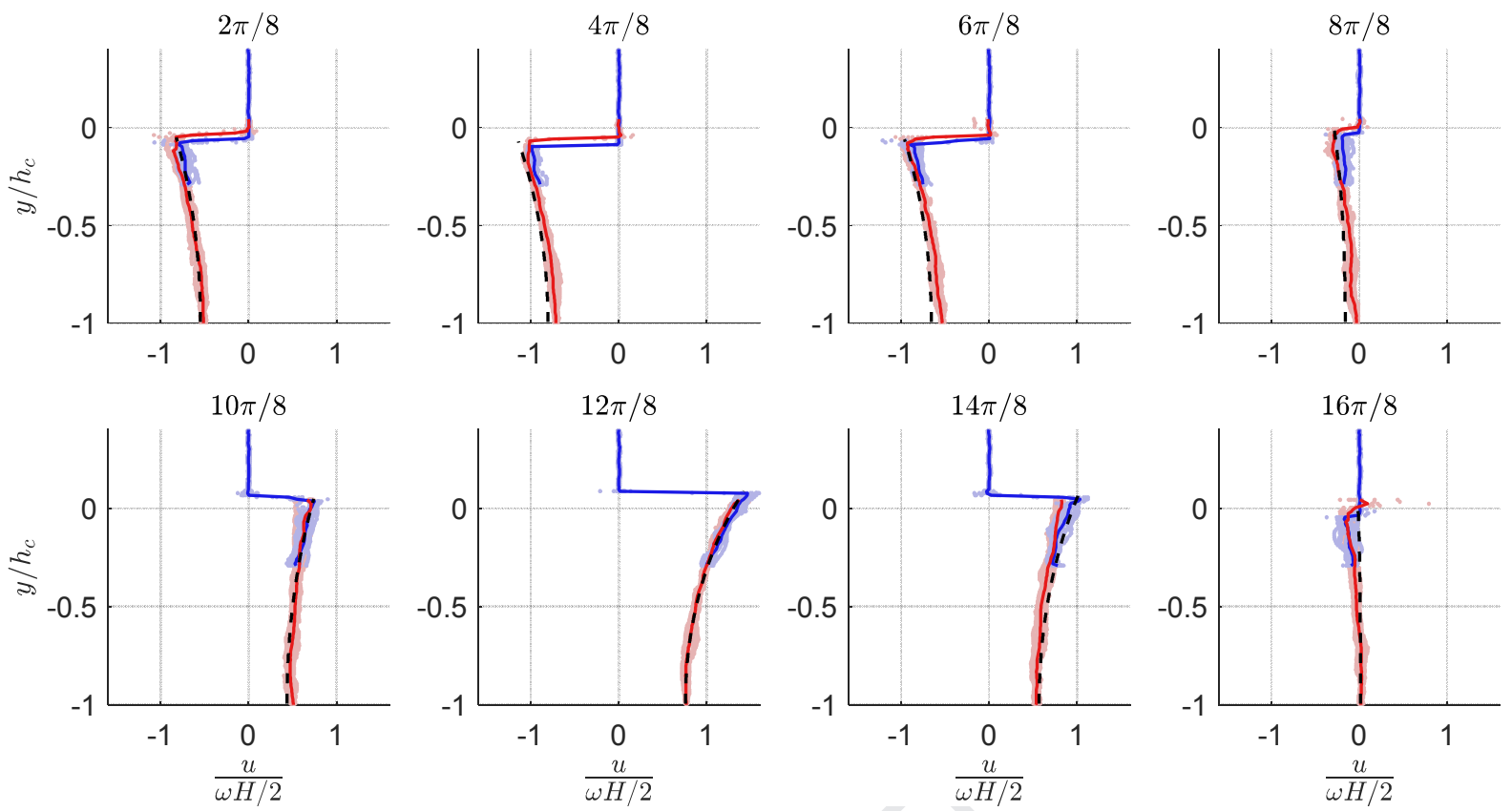

725 Fig. 24 Profiles of horizontal velocity u measured by PIV. Wave period $T=1.0 \mathrm{~s}$, wave height $726 \quad H=0.033$ m (test 1). Red line: lower PIV window. Blue line: Upper PIV Window. Black 727 dashed line represents stream function theory.
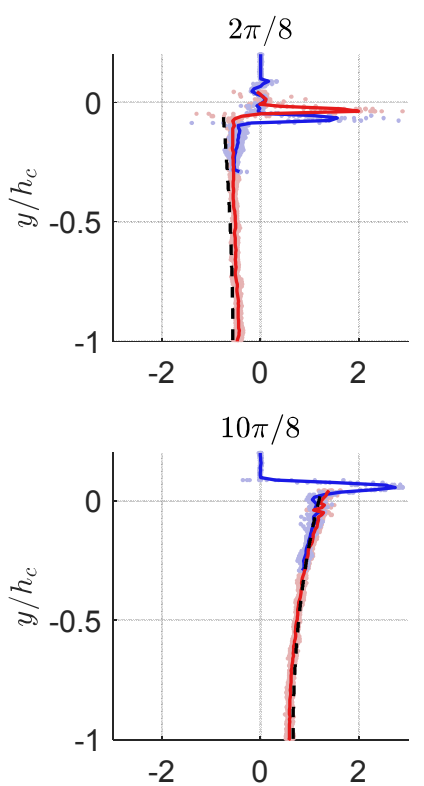

728

729

730

731
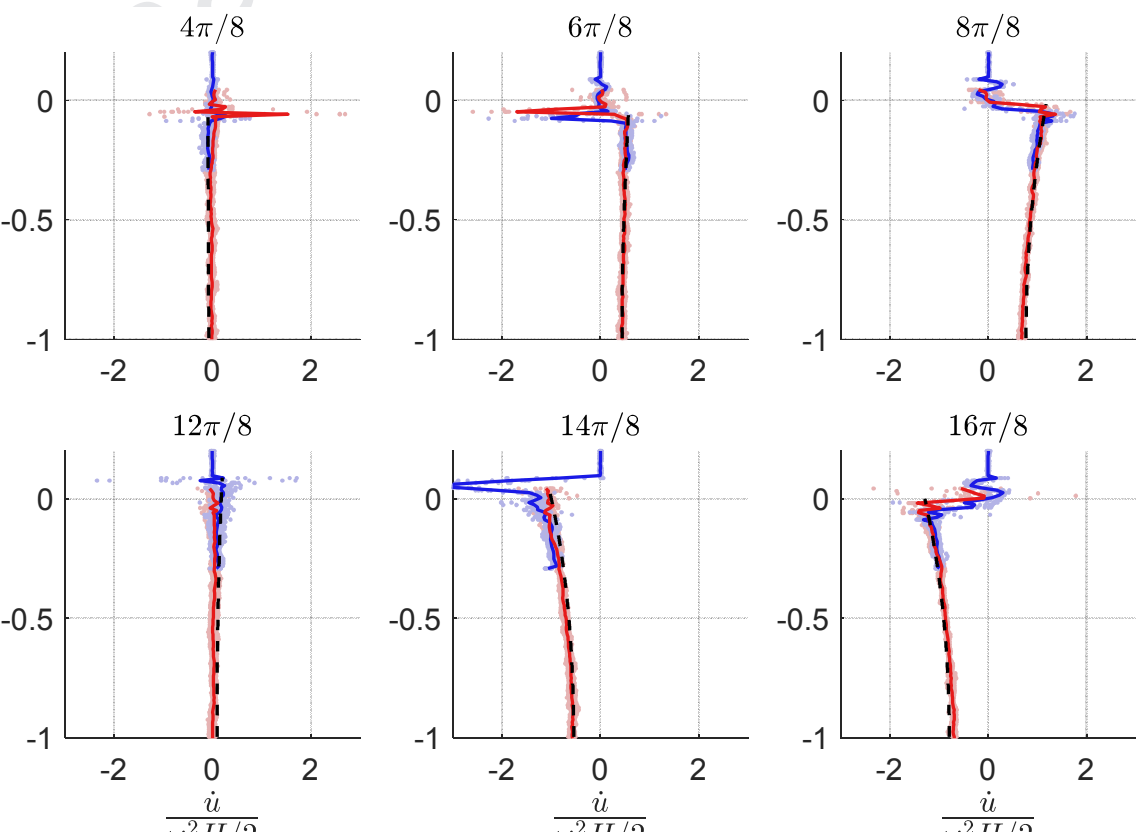

Fig. 25 Profiles of local horizontal acceleration $\partial u / \partial t$ from PIV measurements. Wave period $T=1.0 \mathrm{~s}$, wave height $H=0.033 \mathrm{~m}$ (test 1). Red line: lower PIV window. Blue line: Upper PIV Window. Black dashed line represents stream function theory. 
732

733

734

735

736

737

738

739

$$
u_{i}=\frac{1}{y_{i+1}-y_{i}} \int_{y_{i}}^{y_{i+1}} u d y, \text { and } \frac{\partial u_{i}(t)}{\partial t}=\frac{1}{y_{i+1}-y_{i}} \int_{y_{i}}^{y_{i+1}} \frac{d u(t)}{d t} d y
$$

\subsection{Estimate of local force coefficients}

To determine the force coefficients from our measurements, the method of least squares was used. The method minimizes the mean squared difference between the measured forces and forces predicted through Morisons equation as described in eqs. ( 4.1). (Sumer and Fredsøe, 2006) give an introduction to the least squared method to estimate force coefficients. For the section exposed to the free surface the wetted length of the section $L_{i}(t)$ is described by eqs. ( 2.3). The velocity $u$ and acceleration $\frac{d u(t)}{d t}$ are local quantities, determined through:
740

where $y_{i}$ is the lower position of the section, $y_{i+1}$ is the upper position of the section or the level of the free surface when the section is only partly submerged. Limits on the accuracy made it difficult to conduct a trustworthy estimate of the drag coefficient for small $\mathrm{KC}$ numbers as the contribution to the total force is small for KC-number smaller than 10 .

\subsection{Local inertia force coefficient}

The KC number was generally smaller than 10 and therefore we focused on comparisons of the inertia force coefficient because the contribution from the drag part was in general small. In Fig. 26 the inertia coefficient on the individual sections are presented as a function of KC number for the given section. Only tests with wave kinematics from PIV is included in Fig. 26 , hence the $\mathrm{KC}$ numbers were in the range of 1 to 6 . The Reynolds number was between $7.7 \cdot 10^{3}$ and $3.9 \cdot 10^{4}$, while the $\beta$-number was in the range $4.8 \cdot 10^{3}<\beta<7.2 \cdot 10^{3}$.

Asymptotic theory based on potential theory with a correction for the boundary layer, (Bearman et al., 1986), was included for $\mathrm{KC}<10$, and represents the limit of small KC numbers and large Reynolds number for which the load is inertia dominated. Between $\mathrm{KC}=1$ and $\mathrm{KC}=4$, the measured inertia coefficients group around $C_{M}=2.1$ with a standard deviation of 0.1 . Following asymptotic theory, the theoretical inertia coefficient is $C_{M}=2$. The cylinder was influenced by a degree of diffraction with $\mathrm{D} / \mathrm{L}$ between 0.02 and 0.07 for the tested wave conditions. According to (Sumer and Fredsøe, 2006), the inertia coefficient is slightly larger than the asymptotic value under diffraction. The diffraction effect might explain why the 
measured inertia coefficients group around $C_{M}=2.1$ and not around the asymptotic value of $C_{M}=2$. Viscous effects are other mechanisms that could increase the KC number due to

764 boundary layer velocity deficit at small KC values, as reported in (Bearman et al., 1986) and 765 studied in (Cobbin et al., 1995) for large Reynolds numbers, where the inclusion of the $766 \beta=R e / K C$ suggested that a $C_{M}$ in the range of 2.03-2.07 for the our experiments. For

$767 \mathrm{KC}>5$ the inertia coefficient deviate from asymptotic theory and drops to about $C_{M}=1.8$.

768 The measured inertia coefficients matched well with data from the literature for $\operatorname{Re}=1.7 \cdot 10^{4}$,

769 (Sarpkaya, 1976a) and (Bearman et al., 1985). Interestingly, the inertia coefficient was on the

770 same level for the three sections. This suggests that an inertia coefficient $C_{M}=2.1 \pm 0.1$ is

771 appropriate for all sections of the cylinder. Fig. $26 \mathrm{~b}$ shows the same test cases using wave 772 kinematics estimated from stream function theory. The inertia force coefficient was slightly 773 smaller for $\mathrm{KC}$ in the range from 2-3 compared to the coefficients based on measured wave 774 kinematics.

775

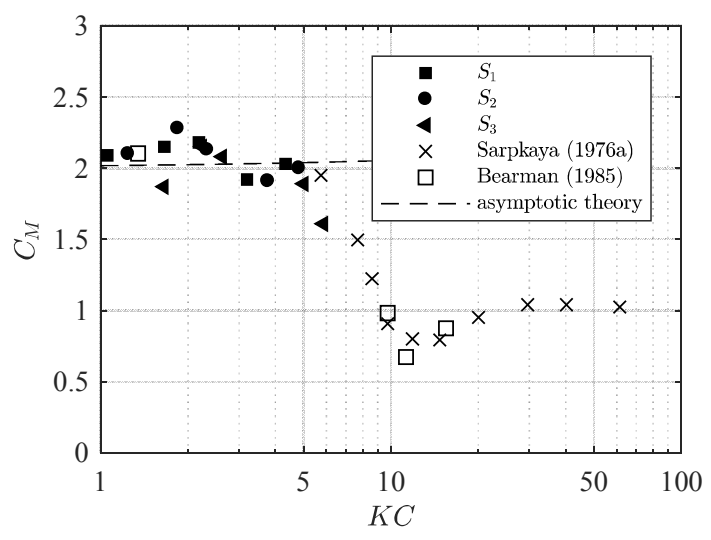

a)

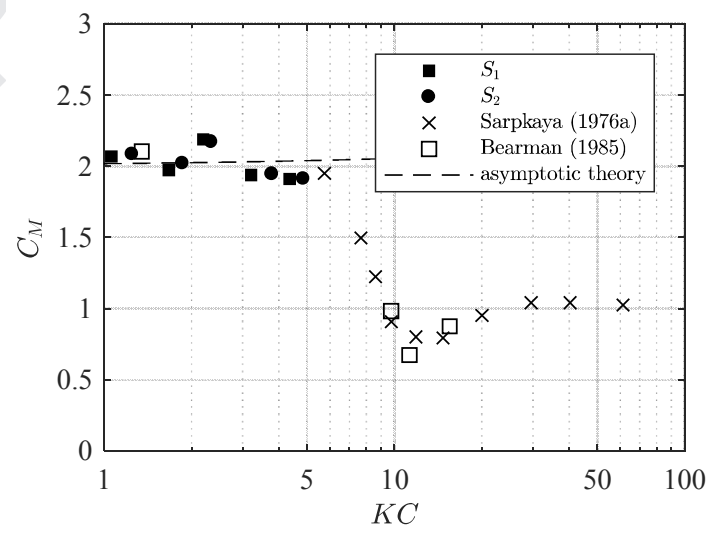

b)

Fig. 26 Inertia force coefficient based on a) measured kinematics, b) Stream function, for the individual sections on the vertical cylinder as a function of KC number. The dashed lines indicate asymptotic theory. Data from literature for $R e=1.7 \cdot 10^{4}$ comprise of $\times$ : (Sarpkaya, 1976a), 口: (Bearman et al., 1985).

Fig. 27 shows the inertia coefficient determined from stream function kinematics and the measured force coefficients. In this case the inertia coefficient did not follow the trend as 
784 found for purely oscillating tests, (Sarpkaya, 1976a) and (Bearman et al., 1985). The abrupt

785

786

787

788

789

790

791

792

793

794

795

796

797

798

799

800

801

802

803

804

805

806 decline at $\mathrm{KC}$ close to 10 was not present in our results. This observation is qualitatively in line with findings presented in (Stansby et al., 1983) and (Bearman et al., 1985). The results clearly showed that the choice of methodology for estimation of wave kinematics even in moderate wave conditions can have some influence on force estimations.

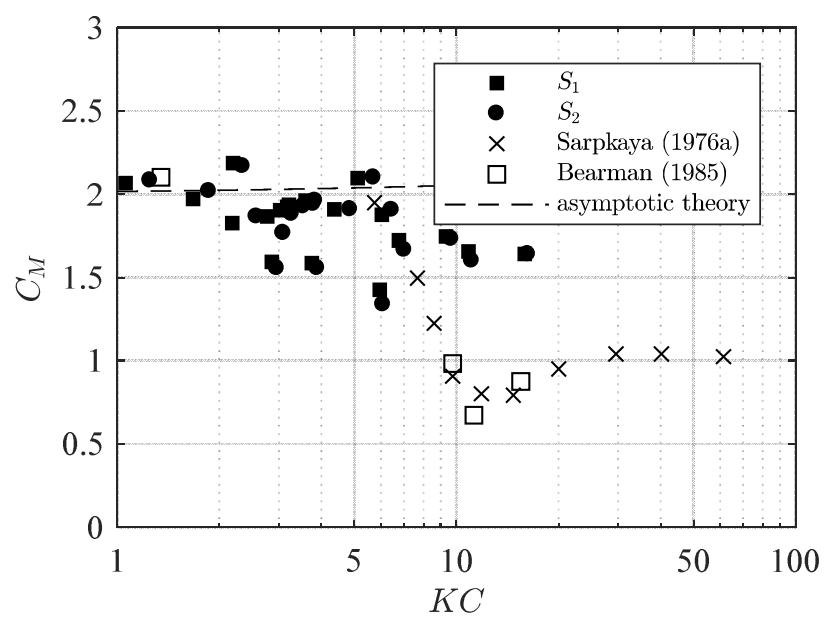

Fig. 27 Force coefficients from stream function kinematics for the individual sections on the vertical cylinder as a function of KC number. The dashed lines indicate asymptotic theory. Data from literature for $R e=1.7 \cdot 10^{4}$ comprise of $\times$ : (Sarpkaya, 1976a), $\square$ : (Bearman et al., 1985).

An attempt was made to study the effect of the orbital motion on the force coefficients. This has earlier been related to the ratio $E=V_{m} / U_{m}$, where $V_{m}$ and $U_{m}$ are the maximum vertical and horizontal velocity, respectively, see (Stansby et al., 1983). The ratio E varied from 0.08 to 0.56 in our experiments based on first order stokes theory, without revealing a dependency of the ratio E. However, this agrees with the findings in (Stansby et al., 1983), where they concluded that data was close to U-tube data for $E \leq 0.7$.

\section{Conclusions}

This study investigated the force distribution on a vertical, circular cylinder by measuring wave loads on individual sections on a vertical, circular cylinder. We measured the wave loads induced by twenty different regular wave conditions. Furthermore, undisturbed wave kinematics were measured for five wave conditions using Particle Image Velocimetry (PIV). 
807 The force distribution was compared to forces estimated by Morison's equation from stream 808 function theory with force coefficients from the literature. From the measured wave kinemat809 ics and wave loads, we determined inertia coefficients on individual sections of the cylinder.

810 From the study, we draw the following conclusions.

812 The time series of local forces revealed large variation in shape between the section closer to 813 the bed and the section exposed to the free surface. For all the wave tests, the steepness of the 814 wave load was more moderate for the section close to the bed compared to the section at the 815 free surface. For a given wave condition, the time at which the wave load was maximum dif-

816 fered at the individual sections. The wave load close to the free surface experienced peak load 817 later than the section close to the bed. Conversely, the minimum force occurred earlier at the 818 section close to the free surface.

820 Force harmonics for the total force agreed with findings in (Kristiansen and Faltinsen, 2017).

821 Note that the different experimental set-up with a slope made it possible to analyse higher 822 wave steepness, H/L, without a fundamental change in the force harmonics. Force harmonics 823 for the individual sections were derived from an overdetermined system of sinusoidal compo824 nents that turned out to be a robust method even for sections only partly submerged. The first 825 harmonic followed approximately the same trend for all three sections with increasing H/L.

826 However, the upper third section the force harmonic experienced a slightly non-linear in-

827 crease with increasing H/L. For $\mathrm{kh}=1.05$ and $\mathrm{kh}=0.84$ the second harmonic was significant828 ly larger at the surface section than on the other two lower sections. In the case with kh= 8290.65 , the second harmonic dramatically increased for $\mathrm{H} / \mathrm{L}>0.05$. This increase related to near830 ly breaking or breaking waves at the vertical cylinder. The third force harmonic showed a less 831 clear trend for increasing wave steepness H/L. Still the upper third section experienced the 832 largest force harmonic for all cases.

834 The wave load distribution was investigated at specific phases of the wave period. For all 835 wave tests, the local force at the two lower sections were comparable to forces estimated with 836 Morison's equation based on stream function theory with force coefficients from (Sarpkaya, 837 1976a). The measured peak wave load on the section exposed to the free surface was general838 ly smaller than the force estimated with Morison's equation with stream function theory. 
840 Motivated by the difference in time $t_{F \max }$ at which the individual sections measured maxi-

841 mum force, a relation between $t_{F \max }$ and the Ursell number was established. We concluded

842 from this study that (i) $t_{F \max }$ increased with Ursell number (ii) the closer to the free surface,

843 the larger the $t_{F \max }$ was.

845 For five test cases, wave kinematics were established from PIV measurements. This included

846 velocity and acceleration fields. Comparisons to both LDV-measurements and stream func847 tion theory documented the methodology as trustworthy. Inertia force coefficients were de-

848 rived on each local section based on the measured wave loads and wave kinematics. The local

$849 \mathrm{KC}$ numbers were in the range $1<\mathrm{KC}<6$ and the Reynolds number was in the range 7.7 .

$85010^{3}<R e<3.9 \cdot 10^{4}$. We concluded that in the range $1<\mathrm{KC}<4$ the inertia coefficient was

$851 C_{M}=2.1 \pm 0.1$ while for $\mathrm{KC}>4 ; C_{M}=1.8 \pm 0.1$. Interestingly, the individual sections ex-

852 posed the same trend of inertia coefficient as a function of $\mathrm{KC}$ number, when using the meas-

853 ured wave kinematics. When force coefficients were derived from stream function theory,

854 they were slightly smaller. When all 20 test cases were used in the estimation of inertia coef-

855 ficients from stream function theory they showed same tendencies as in the literature

856 (Bearman et al., 1985; Stansby et al., 1983), where a gradually decrease from around 2 to

857 around 1.5 in the $\mathrm{KC}$ range from 1 to 16.

858

\section{Acknowledgements}

860 The study was partly supported by the DeRisk project funded by Innovation Fund Denmark, 861 grant number 4106-00038B and partly by DHI. The authors would like to thank master stu862 dents Bárdur Joensen and Rune O. Just for their contributions to the project. 
864

865

866

867

868

869

870

871

872

873

874

875

876

877

878

879

880

881

882

883

884

885

886

887

888

889

890

891

892

893

894

895

\section{References}

Alfonsi, G., Lauria, A., Primavera, L., 2013. On evaluation of wave forces and runups on cylindrical obstacles. J. Flow Vis. Image Process. 20, 269-291.

André, M.A., Bardet, P.M., 2014. Velocity field, surface profile and curvature resolution of steep and short free-surface waves. Exp. Fluids 55. doi:10.1007/s00348-014-1709-5

Aristodemo, F., Tomasicchio, G.R., Veltri, P., 2011. New model to determine forces at onbottom slender pipelines. Coast. Eng. 58, 267-280. doi:10.1016/j.coastaleng.2010.11.004

Arntsen, Ø.A., 1998. Wave Propagation over a Bar and Wave Induced Bed Pressure Gradients. Coast. Eng. 562-575. doi:10.5506/APhysPolB.44.2087

Bearman, P.W., Chaplin, J.R., Graham, J.M.R., Kostense, J.K., Hall, P.F., Klopman, G., 1985. The loading on a cylinder in post-critical flow beneath periodic and random waves, in: Proceedings of the 4th International Conference on Behaviour of Offshore Structures. Delft, The Netherlands, pp. 213-225.

Bearman, P.W., Downie, M.J., Graham, J.M.R., Obasaju, E.D., 1986. Force on a circular cylinder in viscous oscillatory flow at low keulegan — carpenter numbers. J. Fluid Mech. 154, 337-356. doi:10.1017/S0022112086002999

Belden, J., Techet, A.H., 2011. Simultaneous quantitative flow measurement using PIV on both sides of the air-water interface for breaking waves. Exp. Fluids 50, 149-161. doi:10.1007/s00348-010-0901-5

Chakrabarti, S.K., 1980. Inline forces on fixed vertical cylinder in waves. J. Waterw. port, Coast. Ocean Div. 106, 145-155.

Chang, K., Liu, P.L.-F., 1999. Experimental investigation of turbulence generated by breaking waves in water of intermediate depth. Phys. Fluids 11, 3390-3400. doi:10.1063/1.870198

Chang, K.A., Liu, P.L.-F., 1998. Velocity, acceleration and vorticity under a breaking wave. Phys. Fluids 10, 327-329. doi:10.1063/1.869544

Christensen, E.D., Bredmose, H., Hansen, E.A., 2005. Extreme wave forces and wave run-up on offshore wind- turbine foundations, in: Copenhagen Offshore Wind. pp. 1-10.

Christensen, E.D., Hansen, E.A., 2005. Extreme wave run-up on offshore wind-turbine foundations, in: International Conference on Computational Methods in Marine Engineering, MARINE 2005. Oslo, Norway, pp. 293-302. 
896

897

898

899

900

901

902

903

904

905

906

907

908

909

910

911

912

913

914

915

916

917

918

919

920

921

922

923

924

925

926

927

Cobbin, A.M., Stansby, P.K., Duck, P.W., 1995. The hydrodynamic damping force on a cylinder in oscillatory, very-high-Reynolds-number flows. Appl. Ocean Res. 17, 291300. doi:10.1016/0141-1187(96)84791-2

Dingemans, M.W., 1997. Water wave propagation over uneven bottoms. Part 1.: Linear wave propagation. World Sci. Publ.

Easson, W.J., Greated, C.A., 1985. Acceleration measurements using Laser Doppler Anemonetry. SPIE Col. 599 Opt. Eng. Meas. 599, 380-386.

Emarat, N., Christensen, E.D., Forehand, D.I.M., Mayer, S., 2000. A Study of plunging breaker mechanics by PIV measurements and a Navier-Stokes solver, in: Coastal Engineering 2000 - Proceedings of the 27th International Conference on Coastal Engineering, ICCE 2000.

Emarat, N., Forehand, D.I.M., Christensen, E.D., Greated, C.A., 2012. Experimental and numerical investigation of the internal kinematics of a surf-zone plunging breaker. Eur. J. Mech. - B/Fluids 32, 1-16. doi:10.1016/j.euromechflu.2011.09.002

Faltinsen, O.M., Newman, J.N., Vinje, T., 1995. Nonlinear wave loads on a slender vertical cylinder. J. Fluid Mech. 289, 179-198. doi:10.1017/S0022112095001297

Greated, C.A., Skyner, D.J., Bruce, T., 1992. Particle Image Velocimetry (PIV) in the Coastal Engineering Laboratory. Proc. 23rd Conf. Coast. Eng. 23, 212-225.

Griffiths, M., Easson, W., Greated, C., 1992. Measured internal kinematics for shoaling waves with theoretical comparisons. J. Waterw. Port, Coast. Ocean Eng. 118, 280-299. doi:10.1061/(ASCE)0733-950X(1992)118:3(280)

Grue, J., Clamond, D., Huseby, M., Jensen, A., 2003. Kinematics of extreme waves in deep water. Appl. Ocean Res. 25, 355-366. doi:10.1016/j.apor.2004.03.001

Jakobsen, M.L., Dewhirst, T.P., Greated, C.A., 1997. Particle image velocimetry for predictions of acceleration fields and force within fluid flows. Meas. Sci. Technol. 8, 1502-1516. doi:10.1088/0957-0233/8/12/013

Jensen, A., Clamond, D., Huseby, M., Grue, J., 2007. On local and convective accelerations in steep wave events. Ocean Eng. 34, 426-435. doi:10.1016/j.oceaneng.2006.03.013

Jensen, A., Pedersen, G.K., 2004. Optimization of acceleration measurements using PIV. Meas. Sci. Technol. 15, 2275-2283. doi:10.1088/0957-0233/15/11/013

Jensen, A., Sveen, J.K., Grue, J., Richon, J.B., Gray, C., 2001. Accelerations in water waves by extended particle image velocimetry. Exp. Fluids 30, 500-510. 
doi:10.1007/s003480000229

Justesen, P., 1989. Hydrodynamic Forces on Large Cylinders in Oscillatory flow. J. Waterw. Port, Coastal, Ocean Eng. 115, 497-514.

Kim, C.H., Randall, R.E., Boo, S.Y., Krafft, M.J., 1992. Kinematics of $2 \square$ D Transient Water Waves Using Laser Doppler Anemometry. J. Waterw. Port, Coastal, Ocean Eng. 118, 147-165. doi:10.1061/(ASCE)0733-950X(1992)118:2(147)

Kimmoun, O., Branger, H., Zucchini, B., 2004. Laboratory PIV measurements of wave breaking on beach. Isope 14, 293-298.

Kriebel, D.L., 1998. Technical Note Nonlinear Wave Interaction With a Vertical Circular Cylinder : Wave Forces. Ocean Eng. 25, 597-605. doi:Doi 10.1016/S00298018(97)00029-2

Kristiansen, T., Faltinsen, O.M., 2017. Higher harmonic wave loads on a vertical cylinder in finite water depth. J. Fluid Mech. 833, 773-805. doi:10.1017/jfm.2017.702

Kyte, A., Tørum, A., 1996. Wave forces on vertical cylinders upon shoals. Coast. Eng. 27, 263-286. doi:10.1016/0378-3839(96)00003-8

Luck, M., Benoit, M., 2004. Wave loading on monopile foundation for offshore wind turbines in shallow-water areas. Coast. Eng. Proc. 29th Int. Conf. 3992-4004.

Mackwood, P.R., Bearman, P.W., Graham, J.M.R., 1997. Wave and current flows around circular cylinders at large scale, Health and Safety Executive, OTH 491.

Manjula, R., Sannasiraj, S.A., Palanichamy, K., 2013. Laboratory Measurements of Breaking Wave Impact Pressures on a Slender Cylindrical Member. Int. J. Ocean Clim. Syst. 4, $151-169$.

Nelson, R.C., 1994. Depth limited design wave heights in very flat regions. Coast. Eng. 23, 43-59. doi:10.1016/0378-3839(94)90014-0

Perlin, M., He, J., Bernal, L.P., 1996. An experimental study of deep water plunging breakers. Phys. Fluids 8, 2365-2374. doi:10.1063/1.869021

Rienecker, M.M., Fenton, J.D., 1981. A fourier approximation method for steady water waves. J. Fluid Mech. 104, 119-137. doi:10.1017/S0022112081002851

Roos, J., Swan, C., Haver, S., 2010. Wave impacts on the column of a gravity based structure. Proc. ASME 2010 29th Int. Conf. Ocean. Offshore Arct. Eng. OMAE2010.

Sarpkaya, T., 1976a. In-Line and Transverse Forces, On Cylinders in Oscillatory Flow at High Reynolds Numbers. Offshore Technol. Conf. 95-108. 
960

961

962

963

964

965

966

967

968

969

970

971

972

973

974

975

976

977

978

979

980

981

982

983

984

985

986

987

988

989

990

991

Sarpkaya, T., 1976b. Forces on Cylinders Near a Plane Boundary in a Sinusoidally Oscillating Fluid. J. Fluids Eng. 98, 499-505. doi:10.1115/1.3448383

Sarpkaya, T., 1976c. In-line and transverse forces on smooth and sand-roughened cylinders in oscillatory flow at high reynolds numbers, NPS-69SL76062. Monterey, California.

Sawaragi, T., Nochino, M., 1984. Impact Forces of Nearly Breaking Waves on a Vertical Circular Cylinder. Coast. Eng. Japan 27, 249-263.

Stansberg, C.T., Berget, K., Graczyk, M., Muthanna, C., Pakozdi, C., 2012. Breaking wave kinematics and resulting slamming pressures on a vertical column. Proc. Int. Conf. Offshore Mech. Arct. Eng. 679-689.

Stansby, P.K., Bullock, G.N., Short, I., 1983. Quasi-2-D Forces on a Vertical Cylinder in Waves 109, 128-132.

Stansby, P.K., Devaney, L.C., Stallard, T.J., 2013. Breaking wave loads on monopiles for offshore wind turbines and estimation of extreme overturning moment. IET Renew. Power Gener. 7, 514-520. doi:10.1049/iet-rpg.2012.0205

Sumer, B.M., Fredsøe, J., 2006. Hydrodynamics Around Cylindrical Structures (Revised Edition), Advanced Series on Ocean Engineering. World Scientific Publishing Co. Pte. Ltd., New Jersey. London, Singapore, Beijing, Shanhai, Hong Kong, Taipei, Chennai. doi:10.1142/9789812772770

Swan, C., Bashir, T., Gudmestad, O.T., 2002. Nonlinear Inertial loading. Part 1: Accelerations in Steep 2-D Water Waves. J. Fluids Struct. 16, 391-416. doi:10.1006/j

Tanimoto, K., Takahashi, S., Kaneko, T., Shiota, K., 1986. Impulsive Breaking Wave Forces on an Inclined Pile Exerted by Random Waves, in: Edge, B.L. (Ed.), Proceedings of 20th International Conference on Coastal Engineering (ICCE). ASCE, Taipei, Taiwan, pp. 2288-2302.

Ting, F.C.K., Kirby, J.T., 1994. Observation of undertow and turbulence in a laboratory surf zone. Coast. Eng. 24, 51-80.

Tomaselli, P.D., Christensen, E.D., 2017. CFD investigation on the effect of the air entrainment in breaking wave impacts on a monopile, in: ASME (Ed.), Proceedings of the ASME 36th International Conference on Ocean, Offshore and Arctic Engineering (OMAE2017). ASME, Trondheim, Norway, pp. 1-10.

Vested, M.H., Carstensen, S., Christensen, E.D., 2018a. Experimental study of wave force distribution on a monopile structure, in: Proceedings of the 37 th International 
992

993

994

995

996

997

998

999

1000

1001

1002

Conference on Ocean, Offshore and Arctic Engineering, OMAE2018. pp. 1-8.

Vested, M.H., Ergin, F.G., Carstensen, S., Christensen, E.D., 2018b. High-Resolution Planar Two-Component PTV Measurements in a Breaking Wave. Proc. 19th Int. Symp. Appl. Laser Imaging Tech. to Fluid Mech. | Port. JULY 16 - 19, 2018 1-11.

Wienke, J., Oumeraci, H., 2005. Breaking wave impact force on a vertical and inclined slender pile—-theoretical and large-scale model investigations. Coast. Eng. 52, 435-462. doi:10.1016/j.coastaleng.2004.12.008

Williamson, C.H.K., 1985. Sinusoidal flow relative to circular cylinders. J. Fluid Mech. 155, 141-174. doi:10.1017/S0022112085001756 

List of figures:

1004 Fig. 1 Sketch of the wave flume. Waves were generated by a wave paddle to the left and 1005 waves travelled on flat bed for $12.7 \mathrm{~m}$ before shoaling along a 1/25-slope. Six wave gauges 1006 measured the surface elevation. (a) The vertical, circular cylinder positioned $19.8 \mathrm{~m}$ from the wave paddle at a water depth of $h_{C}=0.205 \mathrm{~m}$. (b) PIV window centred $19.8 \mathrm{~m}$ from the wave paddle.

1009 Fig. 2 Sketch of the cylinder. a) Local forces F1 through F5 were measured on the cylindrical

1010 sections connected by load cells. The section number 5 was above water in all wave

1011 conditions and thus measurements on this section are omitted in the following. b) Photograph

1012 of the vertical cylinder installed in the wave flume.

1013 Fig. 3 Illustration of the postion of cylindrical sections relative to the SWL,MWL and surface

1014 elevation $\eta \mathrm{t}$. 10

1015 Fig. 4 Estimation of KC as function of the wave steepness H/L. Left panel: KC number found

1016 from first order stokes theory and maximum and minimum velocities at the surface from

1017 stream function theory. Right panel: KC number based on horizontal particle path. $\mathrm{kh}=0.65$,

$1018 \mathrm{~h} / \mathrm{D}=2.56$

1019 Fig. 5 Estimation of KC as function of the wave steepness H/L at the sea bed. Left panel: KC number found from first order stokes theory and maximum and minimum velocities at the surface from stream function theory. Right panel: $\mathrm{KC}$ number based on horizontal particle path. $\mathrm{kh}=0.65, \mathrm{~h} / \mathrm{D}=2.56$.

1023 Fig. 6 Shoaling of undisturbed wave, wave period $\mathrm{T}=1.0 \mathrm{~s}$, wave height $\mathrm{H}=0.10 \mathrm{~m}$ (test 4).

1024 Black line and grey line represent two runs with the same input parameters at the wave

1025 paddle. The difference in wave height before the slope at WG1 is $1 \%$, while at the PIV

1026 measurement section at WG5, the difference in wave height is $5 \%$

1027 Fig. 7 Shoaling of wave with cylinder (black) and undisturbed shoaling wave (grey), wave period $\mathrm{T}=1.0 \mathrm{~s}$, wave height $\mathrm{H}=0.10 \mathrm{~m}$ (test 4 ). The difference in wave height before the slope at WG1 is $4 \%$, while at the PIV measurement section at WG5, the difference in wave

1031 Fig. 8 Photograph of the PIV setup. Note that the wave gauge is located behind the vertical

1033 Fig. 9 a) Cross-sectional view of the wave flume at the PIV/PTV measurement area. The laser sheet reflected by a mirror at the bottom of the flume and passed through a window in the 
1035 inclined, smooth bed. b) Field of view of the PIV/PTV measurement area with the two overlapping PIV windows, labelled window A and window B.

1037 Fig. 10 Profiles of horizontal velocity measured from PIV (gray) and LDV (black) from the

1038 bed to $0.02 \mathrm{~m}$ below SWL. Wave period $\mathrm{T}=1.0 \mathrm{~s}$, wave height $\mathrm{H}=0.033 \mathrm{~m}$ (test 1$)$. The

1039 shaded areas represent individual PIV runs. The error bars on the LDV results represent the

1040 standard deviation.

1041 Fig. 11 Profiles of local horizontal acceleration, measured by PIV (grey) and LDV (black)

1042 from the bed to $0.02 \mathrm{~m}$ below SWL. Wave period $\mathrm{T}=1.0 \mathrm{~s}$, wave height $\mathrm{H}=0.033 \mathrm{~m}$ (test 1 ).

1043 The shaded areas represent individual PIV runs. The error bars on the LDV results represent

1044 the standard deviation.

1045 Fig. 12 Surface elevation [m] and total wave load [N]. Black full line: Measured data, thin

1046 line: Stream function. (a) Test 1, wave period $\mathrm{T}=1.0 \mathrm{~s}$, wave height $\mathrm{H}=0.033 \mathrm{~m}$. (b) Test 4,

1047 wave period $\mathrm{T}=1.0 \mathrm{~s}$, wave height $\mathrm{H}=0.100 \mathrm{~m}$.

1048 Fig. 13 Time series of surface elevation and measured wave load at section 1, 2, 3 and 4. (a)

1049 Time series of wave test 1 , wave period $\mathrm{T}=1.0 \mathrm{~s}$ and wave height $\mathrm{H}=0.033 \mathrm{~m}$ (b) Time

1050 series of wave test 4 , wave period $\mathrm{T}=1.0 \mathrm{~s}$ and wave height $\mathrm{H}=0.100 \mathrm{~m}$.

1051 Fig. 14 Relative time of maximum load tFmax/T at individual sections, with trend lines..... 24

1052 Fig. 15 Relative time of minimum load tFmin/T at individual sections, with trend lines... 25

1053 Fig. 16 First, second and third harmonics of the wave loads at section 1, 2 and 3. Dashed line

1054 is first harmonics, dashed-dotted line is second harmonics, full line is third harmonics. (a) test

$10551(\mathrm{~b})$ test 4.

1056 Fig. 17 Spectral amplitudes of force harmonics for section 1 through 4 for test 1 . $\circ$ :direct

1057 method, $x$. spectral analyses.

1058 Fig. 18 Spectral components of force harmonics for section 1 through 4 for test 4 . ○:direct method, $x$. spectral analyses.

1060 Fig. 19 Force harmonics for total force as a function of wave steepness H/L

1061 Fig. 20 Force harmonics for the three first section from bottom. Section 1:•, section 2: ○,

1062 section 3: •, as a function of wave steepness H/L...

1063 Fig. 21 Force distribution, wave period $\mathrm{T}=1.0 \mathrm{~s}$ and wave height $\mathrm{H}=0.034 \mathrm{~m}$ (test 1). Black

1064 circles: Measured forces, Full line: Stream function+ Morison equation. 33

1065 Fig. 22 Force distribution, wave period $\mathrm{T}=1.0 \mathrm{~s}$ and wave height $\mathrm{H}=0.098 \mathrm{~m}$ (test 4). Black circles: Measured forces, Full line: Stream function+ Morison equation. 
1067 Fig. 23 Force distribution at maximum total force for four wave cases with $\mathrm{kh}=1.05$. Full

1068 line: Stream function+ Morison force. Markers measured force.

1069 Fig. 24 Profiles of horizontal velocity u measured by PIV. Wave period T = $1.0 \mathrm{~s}$, wave

1070 height $\mathrm{H}=0.033 \mathrm{~m}$ (test 1 ). Red line: lower PIV window. Blue line: Upper PIV Window.

1071 Black dashed line represents stream function theory.

1072 Fig. 25 Profiles of local horizontal acceleration $\partial \mathrm{u} / \partial \mathrm{t}$ from PIV measurements. Wave period

$1073 \mathrm{~T}=1.0 \mathrm{~s}$, wave height $\mathrm{H}=0.033 \mathrm{~m}$ (test 1). Red line: lower PIV window. Blue line: Upper

1074 PIV Window. Black dashed line represents stream function theory. 35

1075 Fig. 26 Inertia force coefficient based on a) measured kinematics, b) Stream function, for the

1076 individual sections on the vertical cylinder as a function of $\mathrm{KC}$ number. The dashed lines

1077 indicate asymptotic theory. Data from literature for $\mathrm{Re}=1.7 \cdot 10^{4}$ comprise of $\times$ : (Sarpkaya,

1078 1976a), $\square$ : (Bearman et al., 1985).

1079 Fig. 27 Force coefficients from stream function kinematics for the individual sections on the

1080 vertical cylinder as a function of $\mathrm{KC}$ number. The dashed lines indicate asymptotic theory.

1081 Data from literature for $\operatorname{Re}=1.7 \cdot 10^{4}$ comprise of $\times$ : (Sarpkaya, 1976a), $\square$ : (Bearman et al., 
Highlights

- Measurements of wave kinematics with PIV

- Measurements of wave force distribution over the depth on a vertical circular cylinder

- Decomposition of force in force harmonics

- Distributed decomposition of force harmonics

- Morison force coefficients in waves 


\section{Declaration of interests}

$\bigotimes$ The authors declare that they have no known competing financial interests or personal relationships that could have appeared to influence the work reported in this paper.

$\square$ The authors declare the following financial interests/personal relationships which may be considered as potential competing interests: 